\title{
Mitochondrial and Nuclear Gene Expression for Cytochrome Oxidase Subunits Are Disproportionately Regulated by Functional Activity in Neurons
}

\author{
Robert F. Hevnera and Margaret T. T. Wong-Riley \\ Department of Cellular Biology and Anatomy, Medical College of Wisconsin, Milwaukee, Wisconsin 53226
}

\begin{abstract}
Mitochondrial respiratory complexes such as cytochrome oxidase $(\mathrm{CO})$ contain both mitochondrial- and nuclear-encoded subunits. To determine whether mitochondrial and nuclear gene expression are regulated proportionately in neurons, we analyzed $C O$ subunit $m R N A$ and mitochondrial DNA (mtDNA) levels by in situ hybridization and grain counting in the visual system of normal and monocular TTX-treated monkeys. We compared the regulation of these molecules with the regulation of $\mathrm{CO}$ activity and $\mathrm{CO}$ protein, analyzed by histochemistry and immunohistochemistry, respectively. In normal animals, $\mathrm{CO}$ activity was in general related more closely to mtDNA and CO subunit I (COI) (mitochondrial-encoded) mRNA levels than to COIV or COVIII (nuclear-encoded) mRNA levels. For example, puffs (also known as blobs) of high $\mathrm{CO}$ activity in striate cortex were enriched in mtDNA and COI mRNA, but not COIV or COVIII mRNA. In 3-7 d TTX-treated animals, proportionate decreases in $\mathrm{CO}$ activity and $\mathrm{CO}$ protein were observed in specific visual centers; these changes were accompanied by disproportionate decreases in COI, COIV, and COVIII mRNA levels. After $7 \mathrm{~d}$ of TTX, COI mRNA fell by $49 \pm 3 \%$ (mean \pm SEM) in LGN neurons, while COIV and COVIII mRNAs fell by only $18 \pm 3 \%$ and $29 \pm 3 \%$, respectively. In comparison, CO activity decreased by $23 \pm 2 \%$, and mtDNA by $26 \pm 4 \%$. Qualitative observations in striate cortex also indicated that COI mRNA changed more than COIV mRNA, COVIII mRNA, mtDNA, or CO activity. Our results suggest that the local distribution of $\mathrm{CO}$ within neurons, and acute regulatory changes in $\mathrm{CO}$ activity occurring over periods of days are controlled mainly by regulation of the mitochondrial genes that encode the catalytic subunits of the enzyme.
\end{abstract}

[Key words: energy metabolism, gene regulation, in situ hybridization, monkey, TTX, visual system]

\footnotetext{
Received June 26, 1992; revised Oct. 16, 1992; accepted Oct. 22, 1992.

We thank Drs. L. Weiss-Wunder and M.-F. Chesselet for providing detailed in situ hybridization protocols, Drs. E. A. Schon and G. Attardi for supplying cytochrome oxidase subunit cDNAs and mitochondrial DNA, Drs. V. M. Haughton and C. Nguyen-minh for providing monkey brain tissue, and Dr. Tom Trusk for his expert assistance with computer systems and image processing. This work was supported by NIH Grants NS18122 and EY05439 to M.T.T.W.-R., and by a fellowship from the Medical Scientist Iraining Program at the Medical College of Wisconsin to R.F.H.

Correspondence should be addressed to Dr. M. Wong-Riley, Department of Cellular Biology and Anatomy, Medical College of Wisconsin, 8701 Watertown Plank Road, Milwaukee, WI 53226.

a Present address: Department of Pathology, Brigham and Women's Hospital, 75 Francis Street, Boston, MA 02115.

Copyright (C) 1993 Society for Neuroscience $0270-6474 / 93 / 131805-15 \$ 05.00 / 0$
}

How are mitochondrial and nuclear gene expression coordinated to yield respiratory complexes containing subunits from both genomes in fixed stoichiometries? This basic cellular problem is distinctly relevant and complex in the context of neuronal biology. Neurons are highly reliant on mitochondrial respiration (Erecinska and Silver, 1989) and are severely affected by disruption of the oxidative pathway, as occurs in the mitochondrial genetic diseases (Harding, 1991). The effective control of mitochondrial function is thus of crucial importance in neurons. However, nuclear-mitochondrial coordination would also seem most complicated in neurons, since many mitochondria reside far from the cell body, in axons and dendrites. In neurons, the nucleus must interact with mitochondria in distinct axonal and dendritic processes that are often thousands of microns or more in length.

We have begun to address the question of nuclear-mitochondrial coordination in neurons using cytochrome oxidase (CO), also known as respiratory complex IV, as a model system. $\mathrm{CO}$ comprises 3 mitochondrial- and 10 nuclear-encoded subunits, present in 1:1 stoichiometry (Kadenbach et al., 1983; Azzi and Müller, 1990; Capaldi, 1990). The enzyme is distributed heterogeneously among and within neurons (reviewed by WongRiley, 1989). Enzyme activity is often lowest in axons and highest in dendrites, though the exact enzyme distribution varies regionally and developmentally (Wong-Riley and Welt, 1980; Kageyama and Wong-Riley, 1982; Carroll and Wong-Riley, 1984; DiFiglia et al., 1987; Mjaatvedt and Wong-Riley, 1988).

Immunohistochemicial studies have shown that the local activity of $\mathrm{CO}$ reflects the local concentration of $\mathrm{CO}$ protein in neurons (Hevner and Wong-Riley, 1989, 1990). The distributions of $\mathrm{CO}$ subunit mRNAs, however, are different from that of the enzyme: in situ hybridization studies have shown that the nuclear-encoded mRNAs for subunits IV (COIV) and VIII (COVIII) are found mainly in cell bodies and proximal dendrites, while the mitochondrial-encoded mRNA for $\mathrm{COI}$ is found throughout the cell body and dendritic tree; mitochondrial DNA (mtDNA) is found in all neuronal compartments (Hevner and Wong-Riley, 1991). These findings suggested that the mitochondrial- and nuclear-encoded subunits are translated to some extent in different subneuronal compartments, and that enzyme assembly and distribution are accomplished posttranslationally.

Further insights have come from studies of $\mathrm{CO}$ regulation. Changes in $\mathrm{CO}$ activity can be induced indirectly by experimental interventions that alter neuronal functional activity (reviewed in Wong-Riley, 1989). For example, monocular retinal impulse blockage with TTX causes $\mathrm{CO}$ activity to decrease in specific regions of the monkey visual thalamus and cortex (Wong- 
Riley and Carroll, 1984). Such changes have been associated with proportionate changes in $\mathrm{CO}$ protein levels, observed after $28 \mathrm{~d}$ of TTX treatment (Hevner and Wong-Riley, 1990). These results indicated that $\mathrm{CO}$ activity is controlled by regulation of CO protein levels (over a period of weeks), and suggested that mIDNA and $\mathrm{CO}$ subunit mRNA levels might be regulated. This last possibility was recently tested using in situ hybridization to analyze expression of mtDNA and mRNA for COI (mitochondrial), COIV (nuclear), and COVIII (nuclear) in normal and 7 d TTX-treated monkeys (Hevner and Wong-Riley, 1991). Decreased levels of mtDNA and all three $\mathrm{CO}$ subunit mRNAs were seen after the TTX treatment.

Our goal in the present study was to compare quantitatively the TTX-induced changes in CO activity, CO protein, mtDNA, and mitochondrial- and nuclear-encoded $C O$ subunit mRNAs. We tested these hypotheses: (1) that $\mathrm{CO}$ activity and $\mathrm{CO}$ protein would change proportionately after 3-7 d of TTX, (2) that regulation of mtDNA and $\mathrm{CO}$ subunit $\mathrm{mRNAs}$ would account for changes in $\mathrm{CO}$ activity, (3) that mitochondrial- and nuclearencoded $\mathrm{CO}$ subunit mRNAs would be regulated proportionately, and (4) that COI mRNA would change in proportion to the mtDNA content. This last hypothesis was suggested by results showing that mitochondrial mRNA and mtDNA levels are proportionately regulated by contractilc activity in muscle (Williams, 1986).

We found that the various subunit mRNAs were regulated disproportionately. The greatest changes were detected in $\mathrm{COI}$ mRNA, a mitochondrial transcript; lesser changes were detected in the nuclear-encoded mRNAs and mtDNA. CO activity and $\mathrm{CO}$ protein decreased proportionately. These findings suggest that, over periods of days to weeks, $\mathrm{CO}$ activity is regulated by complex genetic mechanisms involving differential regulation of CO subunit mRNAs and mtDNA.

\section{Materials and Methods}

Animal tissues. Normal monkey LGN and cortex were obtained from adult male or female macaques (Macaca fascicularis or $M$. radiata) used in a separate, unrelated study and were provided by Drs. V. M. Haughton and $C$. Nguyen-minh (Medical College of Wisconsin). Two adult female macaques $(M$. mulatta $)$ were obtained specifically for the TTX experiments, and were treated with TTX injected into the left vitreous for $3 \mathrm{~d}$ (one injection) or $7 \mathrm{~d}$ (two injections) as described previously (Hevner and Wong-Riley, 1990). Tissues from these same monkeys were also used in an earlier study (Hevner and Wong-Riley, 1991). The animals were deeply anesthetized (ketamine, $20 \mathrm{mg} / \mathrm{kg}$ i.m.; and sodium pentobarbital, $30 \mathrm{mg} / \mathrm{kg}$ i.v. $+30 \mathrm{mg} / \mathrm{kg}$ i.p., or $65 \mathrm{mg} / \mathrm{kg}$ i.v.) and killed by decapitation. Brains were immediately removed, and tissue blocks were dissected free.

Blocks for in situ hybridization were frozen on dry ice and stored at $-80^{\circ} \mathrm{C}$ until sectioning. Blocks for immunohistochemistry were fixed by immersion in $4 \%$ paraformaldehyde, $4 \%$ sucrosc, $0.1 \mathrm{~m}$ sodium phosphate ( $\mathrm{pH} 7.4$ ) on ice, with agitation. After fixation for $4-6 \mathrm{hr}$, the tissues were rinsed in cold $4 \%$ sucrose, $0.1 \mathrm{~m}$ sodium phosphate $(\mathrm{pH}$ 7.4), and then equilibrated with $0.1 \mathrm{M}$ sodium phosphate buffer ( $\mathrm{pH}$ 7.4) with increasing sucrose concentrations $(10 \%, 20 \%, 30 \%)$ as a cryoprotectant to prevent freezing artifact. The blocks were agitated in cold buffer with $30 \%$ sucrose for up to $4 \mathrm{~d}$ before sectioning.

Histochemistry. Free-floating sections, were reacted for $\mathrm{CO}$ histochemistry using diaminohenzidine and cytochrome $c$ as described previously (Wong-Riley, 1979). Cryostat sections were stained by a modification of this procedure (Hevner and Wong-Riley, 1991).

Immunohistochemistry. For immunohistochemistry, only cortex was taken; LGN was not used because relatively few specimens were available, and these were needed for in situ hybridization. Free-floating sections were cut at $30 \mu \mathrm{m}$ and processed for immunohistochemistry using polyclonal antibodies against brain $\mathrm{CO}$. Alternate sections were used for $\mathrm{CO}$ histochemistry. The indirect immunoperoxidase method and diaminobenzidine reaction were used to detect primary antibody binding. Details of the antibodies and immunohistochemical methods have been presented previously (Hevner and Wong-Rilcy, 1989, 1990).

Optical densitometry. Quantitative estimates of CO histochemical and immunohistochemical staining were obtained by densitometry using a Zeiss microscope and Zeiss PI-2 photometer with tungsten lamp illumination. For striate cortex, $30-\mu \mathrm{m}$-thick tangential sections through layer $4 c$ were used. Dark and light ocular dominance columns were identified visually, and ten readings in each type of column were taken for adjacent histochemically and immunohistochemically stained sections. Measurements were taken through a $250-\mu$ m-diameter aperture using a $4 \times$ objective. The background density (measured over an area of slide with no tissue) was subtracted electronically. Lighting conditions were held constant for each section.

For LGN, $10-\mu \mathrm{m}$-thick coronal sections were used. The parvocellular layers (3-6) were studied in each section, and 20-22 neurons were analyzed in cach laycr. Single ncurons wcre isolated, and density measurements were taken through a $25-\mu$ m-diameter aperture using a $25 \times$ objective. The background was subtracted electronically, and lighting conditions were held constant for each section.

In situ hybridization. Both LGN and cortex were studied by in situ hybridization. LGN was sectioned in the coronal plane at $10 \mu \mathrm{m}$ using a cryostat cooled to $-20^{\circ} \mathrm{C}$. Striate cortex was sectioned at $20 \mu \mathrm{m}$ either perpendicular or tangential to the cortical surface. The sections were thaw-mounted onto slides subbed with gelatin (Sigma 300 bloom) and chrome alum, and were immediately refrozen in the cryostat. The slides were stored at $-80^{\circ} \mathrm{C}$ until used for in situ hybridization or CO histochemistry. In every series of five sections, one section each was processed for mtDNA, COI mRNA, COIV mRNA, COVIII mRNA, and CO histochemistry. The series for histochemistry was usually reacted first to identify regions of interest, and selected slides were then processed for in situ hybridization.

Details of the procedures and probes for in situ hybridization were given previously (Hevner and Wong-Riley, 1991). Briefly, we used single-stranded riboprobes labeled to a specific activity of $\sim 3 \times 10^{8} \mathrm{dpm} /$ $\mu \mathrm{g}$ with uridine $5^{\prime}-\left[\alpha^{-35} \mathrm{~S}\right.$-thio $]$ triphosphate $(1250 \mathrm{Ci} / \mathrm{mmol}$; Amersham) in all experiments. Antisense riboprobes were used to hybridize with COI, COIV, and COVIII mRNAs, and sense riboprobes were used to control for nonspecific binding in these experiments. For hybridization with mtDNA, we used COI sense-strand probes on sections that had been treated with RNase and denatured by heating in a buffered dilute salt solution containing 70\% formamide. Control sections for mtDNA experiments were not denatured. The controls for mRNA and mtDNA hybridization showed only low levels of nonspecific riboprobe binding (see Hevner and Wong-Riley, 1991). Also, these probes were previously shown to be specific in blot hybridizations (Hevner and Wong-Riley, 1991).

Slides reacted for in situ hybridization were photographed with darkfield optics except where indicated otherwise.

Computer-assisted grain counting. To obtain quantitative estimates of in situ hybridization signals, silver grains were counted by a modification of the method of Weiss and Chesselet (1989). The method entails collecting digital images of silver grains associated with single cells, and using an image processor to count the silver grains. Image analysis was done at the Imaging Facility of the Medical College of Wisconsin. Images were collected using an SIT video camera (MTI model PA-70) connected to a Leitz microscope with bright-field optics. The video output was digitized with a Perceptics Model 9200 Image Processor. The image processor was controlled using the programs HYPERSCOPE and IPSERVER (Biovision) running on a Macintosh IIfx computer. The digitized images were stored on optical disks, and were processed using the program NIH IMAGE.

For each probe and experiment, the parvocellular layers $(3-6)$ of the left (ipsilateral) LGN were studied in the same section. This allowed us to make comparisons between layers that were exposed to identical conditions of section thickness, fixation, probe concentration, probe specific activity, and hybridization stringency. Comparable regions, generally comprising the central three-fifths of the LGN, were studied in each layer. The region of interest was scanned along a line or lines through each layer, and images of all the neurons along the line were collected. Neurons were identified from the clustering of silver grains, or from Nissl counterstaining used in some sections. Our previous work has shown that neurons are high in mIDNA and CO subunit mRNAs, while glia are low in these molecules and are not significantly labeled 
NORMAL
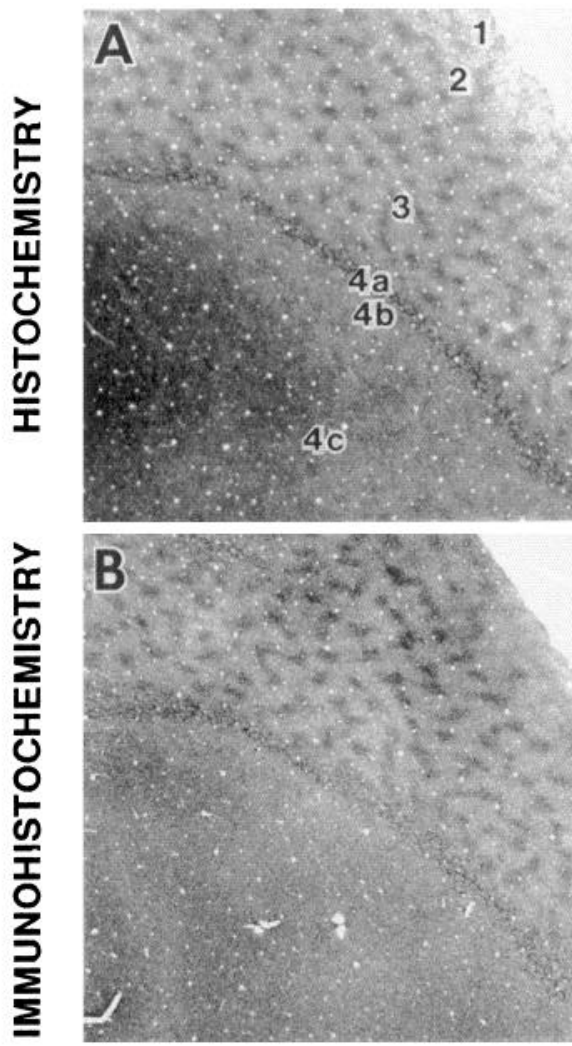

3 DAYS TTX
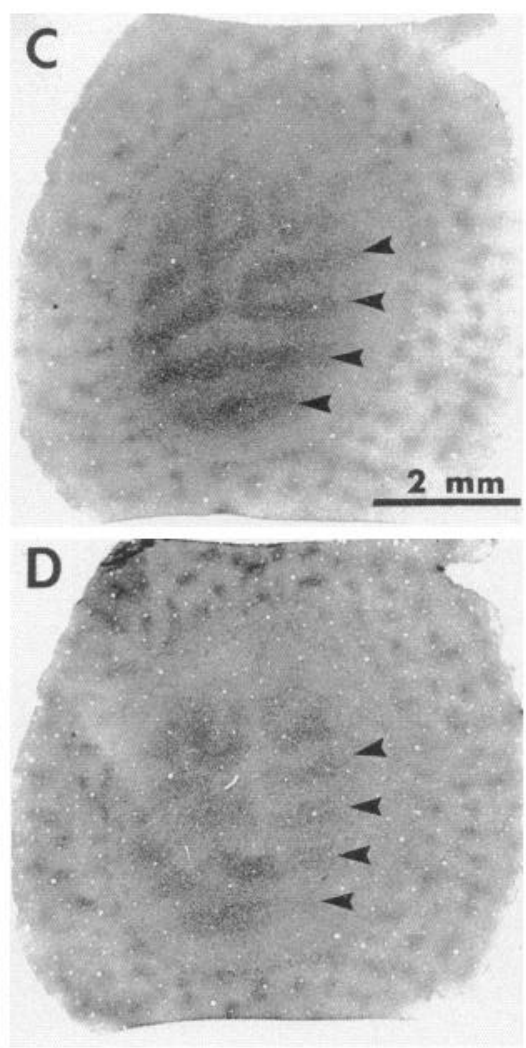

7 DAYS TTX
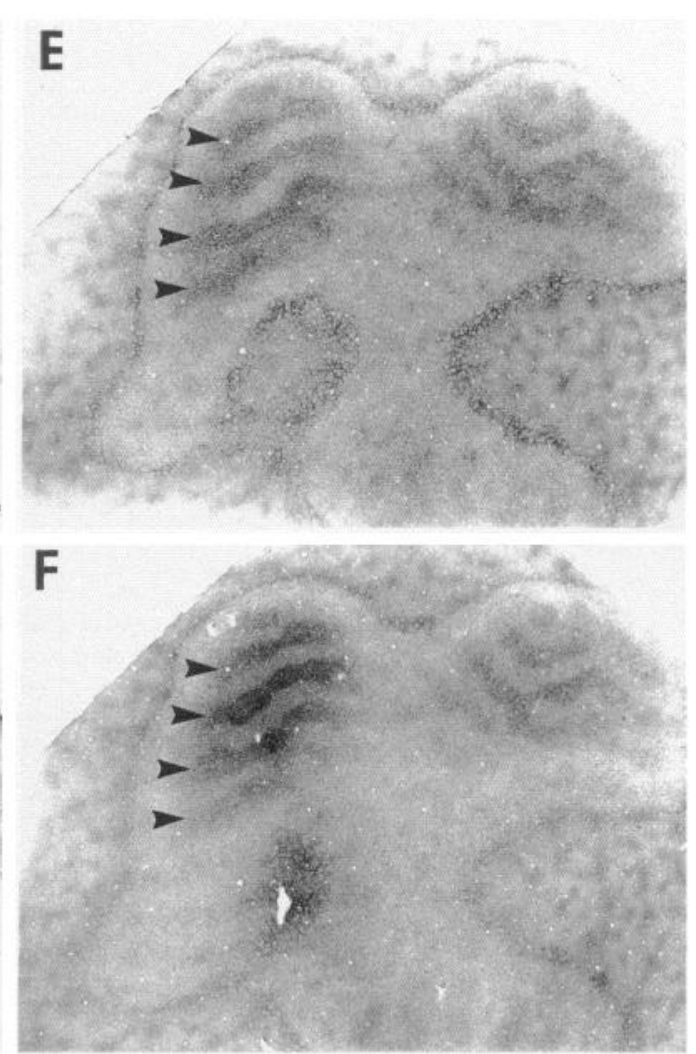

Figure 1. Effects of monocular TTX on CO activity (histochemistry) and CO protein (immunohistochemistry) in adjacent sections of striate cortex. $A$ and $B$, Normal cortex. The histochemical and immunohistochemical patterns matched, indicating that local differences of $C O$ activity reflected underlying differences of CO protein. Note that the puffs (spots of dark staining) in layers 2-3 (layers are labeled in $A$ ) were revealed by both methods, and that layer $4 \mathrm{c}$ showed no evidence of ocular dominance stripes in normal cortex. $C$ and $D$, Cortex after $3 \mathrm{~d}$ of TTX treatment. $\mathrm{CO}$ activity and $\mathrm{CO}$ protein decreased in parallel in layer $4 \mathrm{c}$ ocular dominance columns representing the injected (left) eye, thus generating a striped pattern. Arrowheads indicate dark stripes in layer $4 \mathrm{c}$, corresponding to the untreated eye. $E$ and $F$, Cortex after $7 \mathrm{~d}$ of TTX treatment. More pronounced changes of both $\mathrm{CO}$ actiivity and $\mathrm{CO}$ protein were seen in layer 4c. Ocular dominance banding after $7 \mathrm{~d}$ TTX also extended into layers $2,3,4 \mathrm{a}$, and 5 , as seen by both methods. Changes in CO activity and CO protein were even more remarkable, but still parallel, after $28 \mathrm{~d}$ of TTX (Hevner and Wong-Riley, 1990).

by in situ hybridization over the exposure times used (Hevner and Wong-Riley, 1991). Only sections with even labeling were used.

Images $(512 \times 512$ pixels) were collected at high magnification $(100 \times$ oil immersion objective) to obtain maximal contrast between silver grains and the background. Lighting was held constant between cells within the same experiment. Heterogeneities due to SIT camera response variability were measured by imaging a blank slide, and were substracted digitally from the images of neurons. The cluster of silver grains associated with each neuron was centered within a circle of fixed diameter large enough to enclose single neurons ( $d=250$ pixels). An intensity threshold was set to distinguish between silver grains and background, and was adjusted for slight variations of illumination due to processor response. The number of pixels above threshold was determined and used to calculate the percentage of the circle occupied by silver grains. For each experiment, the background signal due to nonspecific silver grain deposition was measured in three areas of blank slide, averaged, and subtracted from the signal over each neuron.

\section{Results}

Immunohistochemistry: striate cortex

To relate quantitatively the TTX-induced changes of $\mathrm{CO}$ activity and amount, we compared the patterns of $\mathrm{CO}$ histochemical and immunohistochemical staining in adjacent sections of striate cortex from TTX-treated animals after each treatment period, and measured the intensity of staining in cortical layer $4 \mathrm{c}$ by densitometry. We previously found that changes in $\mathrm{CO}$ activity in the visual cortex following $28 \mathrm{~d}$ of TTX treatment were correlated with proportionate changes in the amount of $\mathrm{CO}$ protein (Hevner and Wong-Riley, 1990); in the present study, we extended our analysis to 3 and $7 \mathrm{~d}$ of TTX.

Figure 1 shows the histochemical and immunohistochemical patterns from normal and 3-7 d TTX-treated monkeys. Following TTX treatment, $\mathrm{CO}$ activity decreased most in layer $4 \mathrm{c}$ ocular dominance columns related to the injected eye, as observed previously (Wong-Riley and Carroll, 1984; Hevner and Wong-Riley, 1990). Alternating columns of high and low CO activity were clearly visible in both TTX-treated animals (Fig. $1 C, E$ ), but not in normals (Fig. $1 A$ ). The amount of $\mathrm{CO}$ protein, shown immunohistochemically, changed in parallel with $\mathrm{CO}$ activity: virtually identical patterns were seen by histochemistry (Fig. $1 A, C, E$ ) and immunohistochemistry (Fig. $1 B, D, F$ ) for each TTX treatment period. The magnitude of the changes increased with treatment duration.

The densitometric data, shown in Figure 2, suggested that changes in $\mathrm{CO}$ activity were entirely due to changes in the amount of CO protein. The optical density of staining was measured in light (deprived-eye) and dark (intact-eye) columns through a 


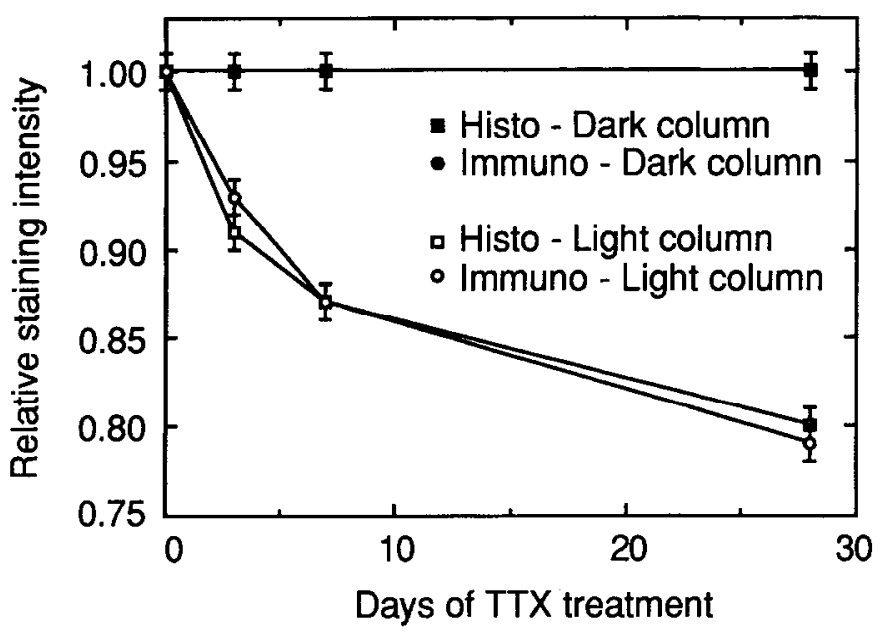

Figure 2. Densitometric measurement of monocular TTX effects on $\mathrm{CO}$ activity (histochemistry) and $\mathrm{CO}$ protein (immunohistochemistry) in striate cortex. Staining intensity was measured densitometrically in light (treated eye) and dark (untreated eye) layer $4 \mathrm{c}$ ocular dominance columns in adjacent histochemically and immunohistochemically reacted sections (shown in Fig. 1). Normal cortex had no ocular dominance banding, so only one set of measurements was taken for each stain. Readings were normalized to give a mean intensity in dark columns of 1.00. The graph shows that the histochemical and immunohistochemical staining density in light columns decreased in parallel at each treatment period. This suggests that $\mathrm{CO}$ activity and $\mathrm{CO}$ protein fell in direct proportion, and that the $\mathrm{CO}$ protein changes fully accounted for the $\mathrm{CO}$ activity changes. Values plotted are mean \pm SEM of 20-22 readings. All differences between light and dark column intensities were significant ( $p<0.001$, Student's $t$ test, two-tailed). The data for the $28 \mathrm{~d}$ TTXtreated animal were reported previously (Hevner and Wong-Riley, 1990) and are included here for comparison with the earlier time points.

250- $\mu \mathrm{m}$-diameter circular aperture. After each TTX treatment period, the percentage decrease of staining intensity in deprivedeye columns relative to intact-eye columns was about the same for both histochemistry and immunohistochemistry. For example, after $7 \mathrm{~d}$ of TTX, histochemical and immunohistochemical staining both decreased by $13 \pm 4 \%$ in light columns relative to dark columns. Such parallel changes indicate that enzyme activity changes were secondary to regulation of enzyme protein amount; modulation of enzyme molecular activity appeared to play little or no role. However, since it is presently unknown if staining intensity is strictly proportional to $\mathrm{CO}$ activity and $\mathrm{CO}$ protein, effects on the molecular activity of the enzyme cannot be completely ruled out based on these data. Furthermore, other mechanisms could still be involved during treatment periods less than $3 \mathrm{~d}$.

\section{In situ hybridization: $L G N$}

Our previous study showed that changes in mtDNA and $\mathrm{CO}$ subunit mRNAs were induced in cortex by TTX treatment for $7 \mathrm{~d}$ (Hevner and Wong-Riley, 1991). In the present study, we wished to obtain further information about the quantitative magnitude of such changes over TTX treatment periods from 3-7 d. We used in situ hybridization to label mRNAs and mtDNA in LGN and cortex, and then used grain counting to measure quantitatively the mRNA and mtDNA levels in neurons in different LGN layers receiving input from the intact eye, or from the TTX-treated eye. We also measured changes in CO activity, using histochemistry and densitometry.

Figure 3 shows the distributions of CO activity, mtDNA, COI mRNA (mitochondrial), COIV mRNA (nuclear), and COVIII mRNA (nuclear) in LGN from normal and $7 \mathrm{~d}$ TTX-treated monkeys. In normals, each of the markers was present at about the same level in the different LGN layers (Fig. $3 A, D, G, J, M$ ). Exceptions were $\mathrm{CO}$ activity and COI mRNA, which were both higher in layer 1 than in other LGN layers. CO activity was also found to be highest in layer 1 of the normal LGN in a previous histochemical and densitometric study (Liu and Wong-Riley, 1990).

Following TTX treatment, parallel changes of all tive markers were observed in specific LGN layers (Fig. 3). Different laminae were affected in the ipsilatcral and contralateral LGN, in accordance with the connections from each eye to layers 2,3 , and 5 of the ipsilateral LGN, and to layers 1, 4, and 6 of the contralateral LGN (reviewed by Hubel and Wiesel, 1977). Changes in the ipsilateral and contralateral LGN are shown for the $7 \mathrm{~d}$ TTX-treated animal in Figure 3; similar but less dramatic changes were seen in the $3 \mathrm{~d}$ TTX-treated animal (not shown). CO activity was decreased in layers 2,3 , and 5 of the ipsilateral LGN (Fig. $3 B$ ), and in layers 1,4 , and 6 of the contralateral LGN (Fig. $3 C$ ), confirming previous results (Wong-Riley and Carroll, 1984; Hevner and Wong-Riley, 1990). The same pattern of laminar changes was seen for mtDNA and for the three $\mathrm{CO}$ subunit mRNAs. Each of the markers changed more in the ipsilateral than in the contralateral LGN, as observed previously for $\mathrm{CO}$ activity and $\mathrm{CO}$ protein (Wong-Riley and Carroll, 1984; Hevner and Wong-Riley, 1990). Of the five markers, COI mRNA

\footnotetext{
Figure 3. Effects of monocular TTX ( $7 \mathrm{~d}$ ) on CO activity, mtDNA, and CO subunit mRNA levels in the LGN. $A-C$, CO activity (histochemistry). In the normal LGN $(A)$, enzyme activity was about the same in cach laycr (numbercd in $A$ ), except in layer 1 , where CO activity was highest. In the TTX-treated animal, enzyme activity was reduced in layers 2,3 , and 5 of the ipsilateral LGN $(B)$, and in layers 1,4 , and 6 of the contralateral LGN $(C)$. These changes were more prominent in the ipsilateral than in the contralateral LGN, as noted in previous studies (Wong-Riley and Carroll, 1984; Hevner and Wong-Riley, 1990). Asterisks indicate normal enzyme activity in layers receiving input from the untreated eye. $D-F$, mtDNA. All six layers had similar mtDNA levels in the normal LGN $(D)$. TTX treatment induced mtDNA to decrease in the treated-eye layers of the ipsilateral $(E)$ and contralateral $(F)$ LGN. Note the relatively diffuse distribution of mtDNA within the LGN layers, with only slightly increased labeling over cell bodies. Ipsilateral changes were greater than contralateral changes. $G-I$, COI mRNA. In the normal LGN $(G)$, COI mRNA levels were highest in layer 1, but were about equal in other layers. After TTX treatment, marked reductions of COI mRNA were seen in the treated-eye layers of the LGN, both ipsilaterally $(H)$ and contralaterally $(I)$, though the ipsilateral changes were greater. COI mRNA was detected throughout the neuropil of each LGN layer, but was most concentrated in cell bodies, which appear as bright punctate in the figure. $J-L$, COIV mRNA. Layers of the normal LGN $(J)$ contained about equal levels of COIV mRNA. In the TTX-treated monkey, COIV mRNA was decreased in treated-eye layers of the ipsilateral $(K)$ and contralateral $(L)$ LGN. COIV mRNA appeared to change least of all the markers, and changes were barely visible contralaterally $(L)$. The apparent punctate distribution of COIV mRNA at this magnification reflects its localization in cell bodies and proximal dendrites. $M-O$, COVIII mRNA. Like other markers, COVIII mRNA was evenly distributed in layers of normal LGN ( $M$ ), but decreased in treated-eye layers of the ipsilatcral $(N)$ and contralatcral $(O)$ LGN after TTX. Like COIV mRNA, COVIII mRNA was localized mainly or exclusively in cell bodies and proximal dendrites, and thus had a punctate distribution at the magnification shown.
} 


\section{NORMAL}
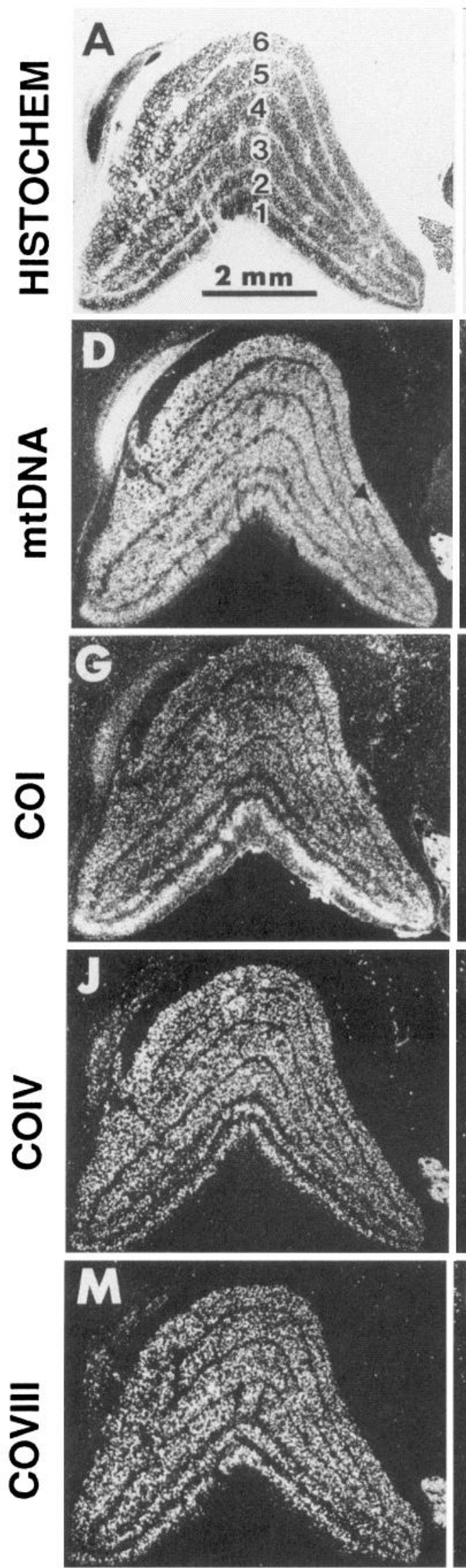

\section{TTX - IPSI}

B
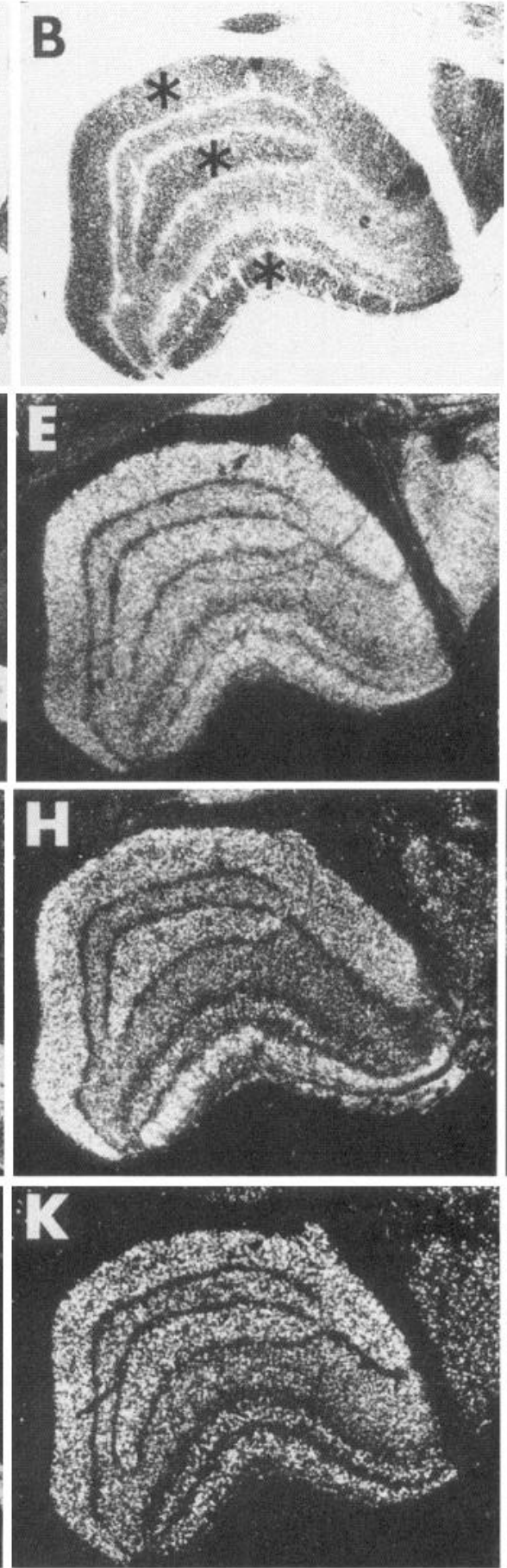

\section{N}

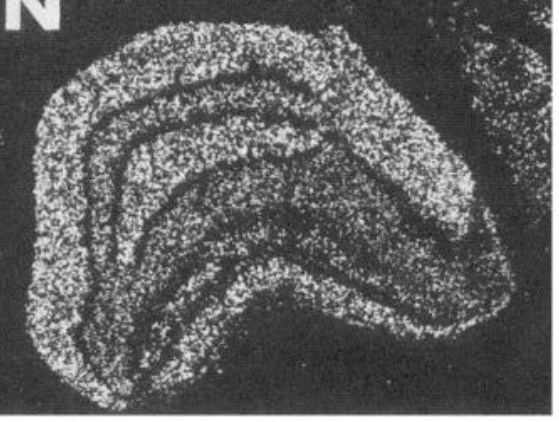

\section{TTX - CONTRA}
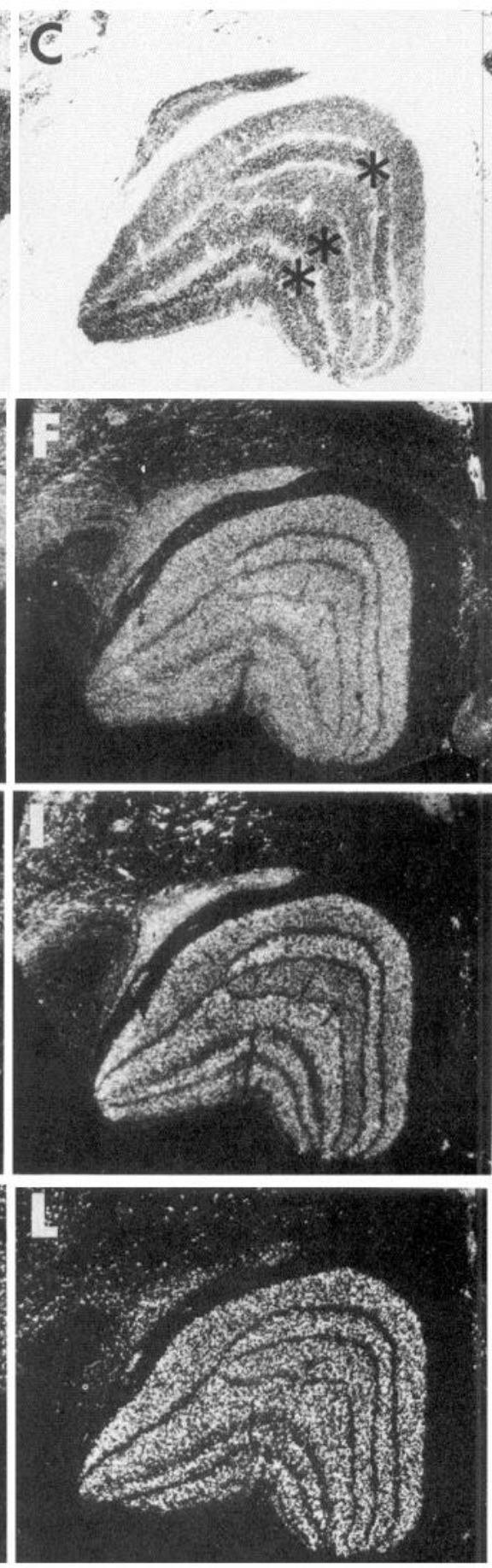

(2)

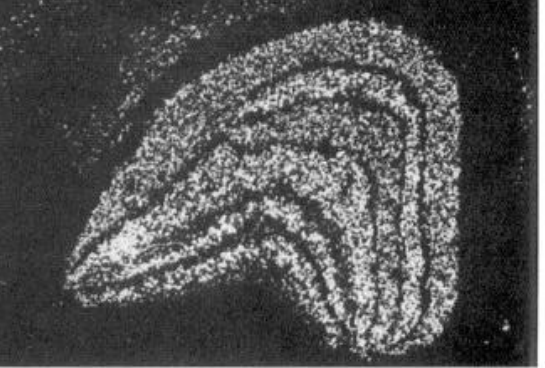



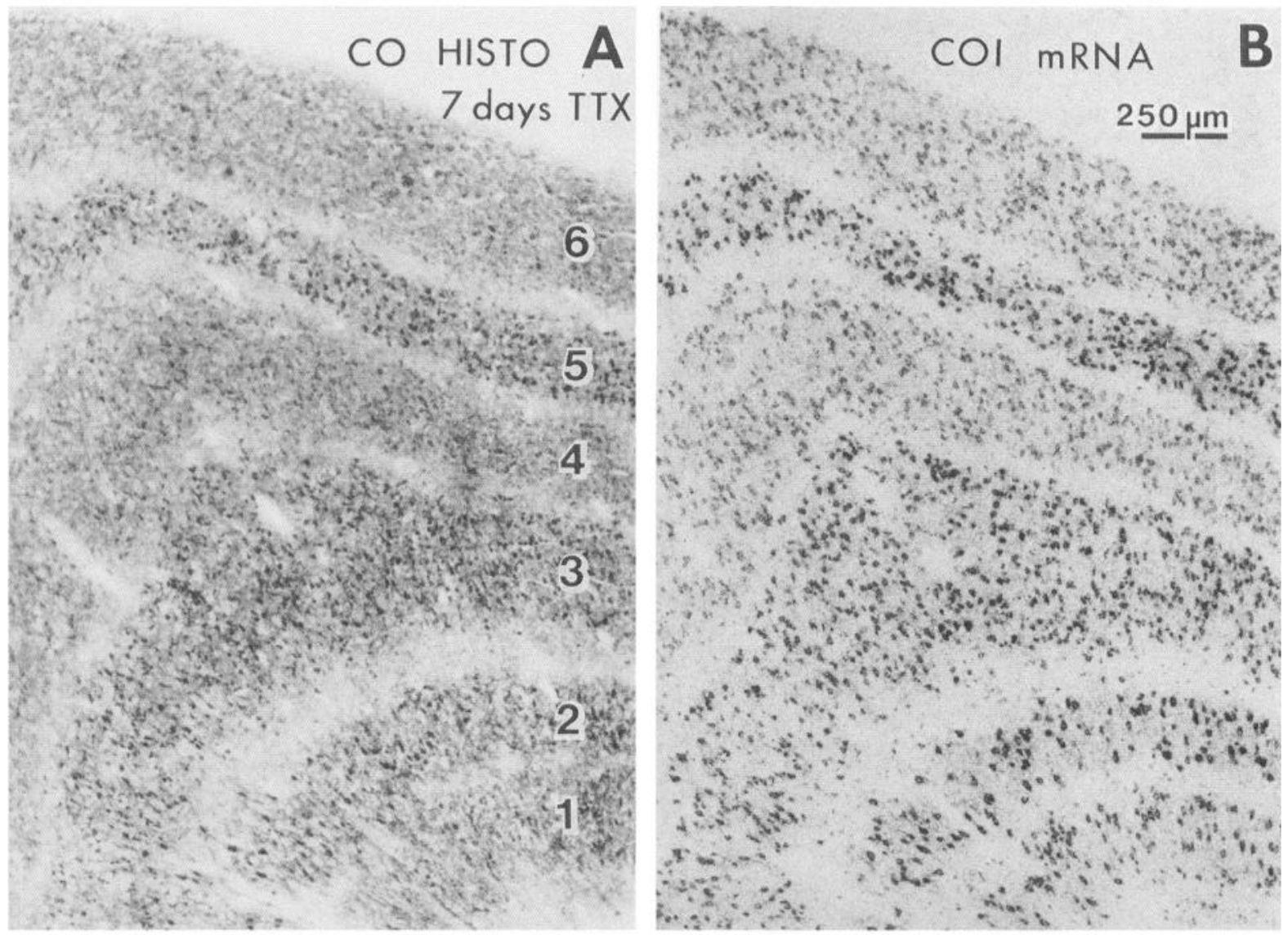

Figure 4. Neuropil and cellular localization of CO activity and COI mRNA in the contralateral LGN after $7 \mathrm{~d}$ of TTX. $A$, CO activity (histochemistry). Enzyme activity was high in many cell bodies, and was generally moderate in the neuropil. TTX treatment induced CO activity to decrease in layer 1 relative to layer 2 (magnocellular layers), and in layers 4 and 6 relative to layers 3 and 5 (parvocellular layers). The layers with reduced enzyme activity received input from the treated eye. Cell bodies were most affected; enzyme activity in the neuropil decreased less or not at all. $B$, COI mRNA. This mRNA was concentrated in neurons (darkly labeled dots in each layer), but was also present in neuropil (diffuse faint labeling in each layer). Magnocellular layer 1, and parvocellular layers 4 and 6 , showed sharply decreased COI mRNA labeling in neurons, but little or no change in the neuropil. Bright-field optics; exposure time, 3 weeks.

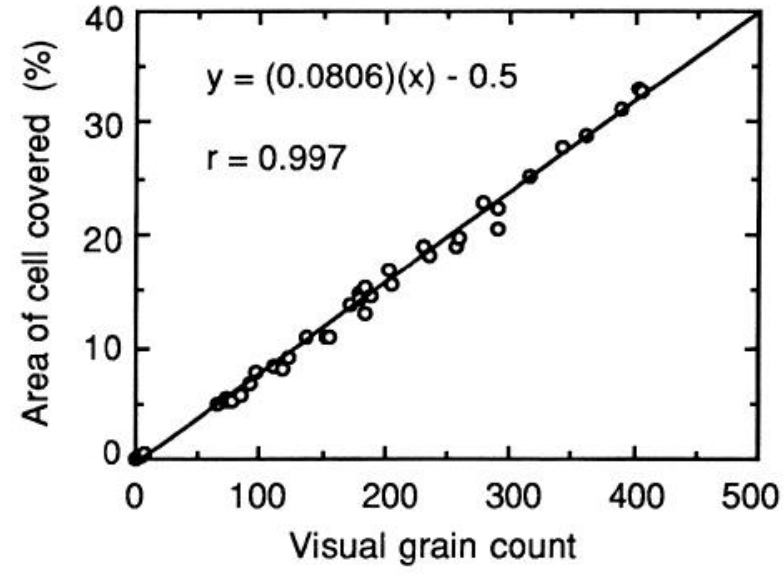

Figure 5. Correlation of computer-assisted grain area measurements with visual grain counts. Images of silver grains overlying neurons were collected from in situ hybridization-reacted slides as described in Materials and Methods. The images were processed by computer to remove background densities and to identify areas for analysis. The number of silver grains was estimated from the percentage of area covered by grains in a circular region centered over a neuronal cell body. The number of silver grains was also counted visually in 40 images. The graph shows that the computer areal measurement was highly correlated with the visual grain count, and therefore provided an accurate estimate of the number of silver grains. appeared to change most (Fig. $3 H, I$ ), and COIV mRNA changed least (Fig. $3 K, L$ ).

Some of the subtle mRNA changes detected by in situ hybridization were best shown with bright-field illumination. Figure $4 B$ shows an example of COI mRNA labeling in the contralateral LGN of the $7 \mathrm{~d}$ TTX-treated monkey photographed with bright field. An adjacent CO-stained section is shown in Figure $4 A$. The COI mRNA labeling was clearly most intense in the cell bodies, but was also seen in the neuropil of each layer. The bright-field illumination also shows that the COI mRNA labeling in layers 1,4 , and 6 decreased mostly in cell bodies, rather than in neuropil (Fig. $4 B$ ). CO activity also appeared to change more in cell bodies than in neuropil (Fig. $4 A$ ). Note that, even though layer 1 had the highest COI mRNA levels in normal LGN (Fig. $3 G$ ), this layer had lower levels of COI mRNA compared to layer 2 after TTX treatment (Figs. 3I, 4B).

The localization of COI mRNA in cell bodies and neuropil confirms previous results based on studies of the hippocampus and cerebellum (Hevner and Wong-Riley, 1991). The present results were also consistent with our previous findings that mtDNA is present throughout neurons (including cell bodies, dendrites, and axons), and that COIV and COVIII mRNAs are localized mainly or exclusively in cell bodies and proximal dendrites (Hevner and Wong-Riley, 1991). 


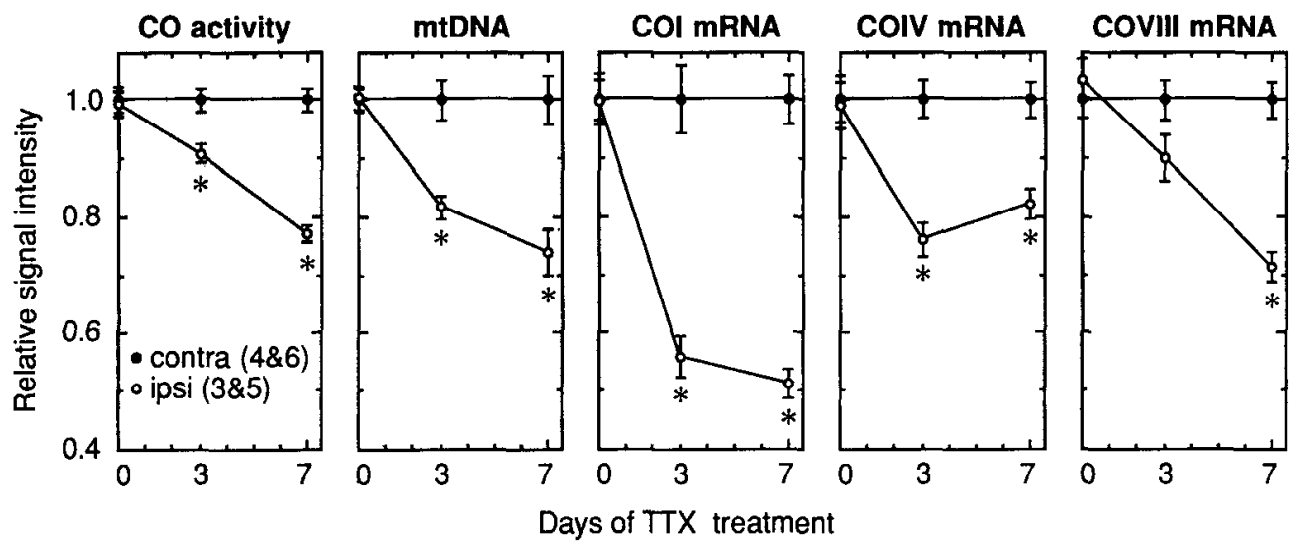

Figure 6. Quantitative measurement of monocular TTX effects on CO activity, mtDNA, and CO subunit mRNAs in LGN neurons. Individual neurons in the parvocellular layers (3-6) of the ipsilateral LGN from normal and 3-7 d monocular TTX-treated monkeys were analyzed for CO activity (histochemistry) by densitometry, and for mtDNA and CO subunit mRNAs by computer-assisted grain counting. For each marker, 22 neurons were analyzed in each layer. Neurons were grouped according to innervation from the contralateral, untreated eye (layers 4 and 6), or from the ipsilateral, treated eye (layers 3 and 5). Measurements were normalized to give a mean relative signal in the contralateral input group of 1.0 . The graphs show that monocular TTX induced significant decreases of each marker in neurons receiving input from the treated eye. The mitochondrial- (COI) and nuclear-encoded (COIV, COVIII) mRNAs did not fall by the same amount. Rather, COI mRNA fell 1.5- to 4-fold more than COIV or COVIII mRNA, depending on the treatment period. Values shown are mean \pm SEM of 44 measurements. Significant differences ( $p<0.05$, Student's $t$ test, two-tailed) between ipsilateral and contralateral input groups are indicated by an asterisk (each indicated difference was also significant to $p<0.001$ ).

\section{Grain counting: $L G N$}

We quantified TTX-induced changes in mtDNA and CO subunit mRNA levels by computer-assisted grain counting in LGN slides processed for in situ hybridization, and we quantified changes in $\mathrm{CO}$ activity by optical densitometry. Since COIV and COVIII mRNAs were concentrated in cell bodies, and COI mRNA also changed most in cell bodies, measurements were taken over cell bodies only. This would also minimize the measurement of possible changes in mtDNA levels in axon terminals arriving from the retina; mtDNA is detected in axon terminals, but CO subunit mRNAs are not (Hevner and Wong-Riley, 1991).

For grain counting, digital images of silver grains over single neurons were collected and processed by computer. The number of silver grains was determined in a circular region (diameter, 250 pixels) from the percentage of area covered by grains (measured by computer). The accuracy of this method was tested by counting grains visually in 40 images, and then using the computer to calculate the area covered by the silver grains. As shown in Figure 5, these two measures were highly correlated $(r=$ $0.997)$, indicating that the areal calculation was a valid estimate of the grain count.

Grain counts for each probe were taken from 22 neurons in each of the parvocellular layers (3-6) of the left (ipsilateral) LGN from normal, $3 \mathrm{~d}$ TTX-treated, and $7 \mathrm{~d}$ TTX-treated animals. The magnocellular layers were not analyzed by grain counting. Comparisons were made only between layers in the same section, which were therefore exposed to identical experimental conditions.

Results of the grain counts, and of the densitometric readings for CO histochemistry, are shown in Figure 6. For each marker, the layers are grouped according to innervation from the ipsilateral (layers 3 and 5) or contralateral (layers 4 and 6) eye. These quantitative data (Fig. 6) confirm that levels of each marker decreased with TTX treatment, as was concluded from visual examination of the slides (Fig. 4). In the normal LGN, no difference between ipsilateral and contralateral eye-input layers was found for any of the markers. Comparisons between individual layers also failed to reveal any significant differences of neuronal $\mathrm{CO}$ histochemical staining density. Differences in $\mathrm{CO}$ activity between parvocellular layers were detected in a previous study using larger sample sizes (Liu and Wong-Riley, 1990). In normal LGN, the only significant laminar difference found for any of the markers was for COI mRNA, which was qualitatively higher in magnocellular layer 1 than in other LGN layers (Fig. $3 G$ ). This accords with our previous finding that $\mathrm{CO}$ activity is highest in layer 1 (Liu and Wong-Riley, 1990).

After $3 \mathrm{~d}$ of TTX, neurons in the layers receiving input from the treated eye contained significantly decreased levels of all of the markers, except COVIII mRNA (Fig. 6). The largest drop occurred in COI mRNA, which fell to $55.8 \pm 3.5 \%$ of normal after $3 \mathrm{~d}$ of treatment ( $p<0.001$, Student's $t$ test, two-tailed). By comparison, $\mathrm{CO}$ activity decreased to $90.8 \pm 1.6 \%$ of normal over the same treatment period $(p<0.001)$. Also, a surprisingly large decrease in mtDNA to $81.7 \pm 2.0 \%$ of normal was observed $(p<0.001)$. The COIV mRNA fell to about $76 \%(p<$ 0.001 ), and the COVIII mRNA to about $90 \%$ of normal (this change was not statistically significant, $p=0.06$ ). Thus, $\mathrm{CO}$ activity actually changed less than mtDNA or any of the $\mathrm{CO}$ subunit mRNAs after $3 \mathrm{~d}$ of TTX treatment.

After $7 \mathrm{~d}$ of TTX, CO activity, mtDNA, and COVIII mRNA decreased further; COI and COIV mRNAs, however, remained steady between 3 and $7 \mathrm{~d}$ of treatment (Fig. 6). After $7 \mathrm{~d}$, CO activity had fallen to $77 \pm 1.5 \%$ of normal, mtDNA to $73.8 \pm$ $3.9 \%$ of normal, and COVIII mRNA to $71.4 \pm 2.5 \%$ of normal levels ( $p<0.001$ compared to normal, in each case). COI mRNA decreased to $51.1 \pm 2.5 \%$ of normal $(p<0.001)$, while COIV mRNA increased nonsignificantly hetween 3 and $7 \mathrm{~d}$ of TTX, to $82.1 \pm 2.6 \%$ of normal ( $p<0.001$ compared to normal). Thus, maximal regulation of COI and COIV mRNAs occurred rapidly (within about $3 \mathrm{~d}$ of TTX treatment), while the time course of changes in CO activity, mtDNA, and COVIII mRNA appeared slower. The greatest change after $7 \mathrm{~d}$ of treatment, as after $3 \mathrm{~d}$, was in COI mRNA, while the smallest change was in 
NORMAL

TTX - 7 DAYS
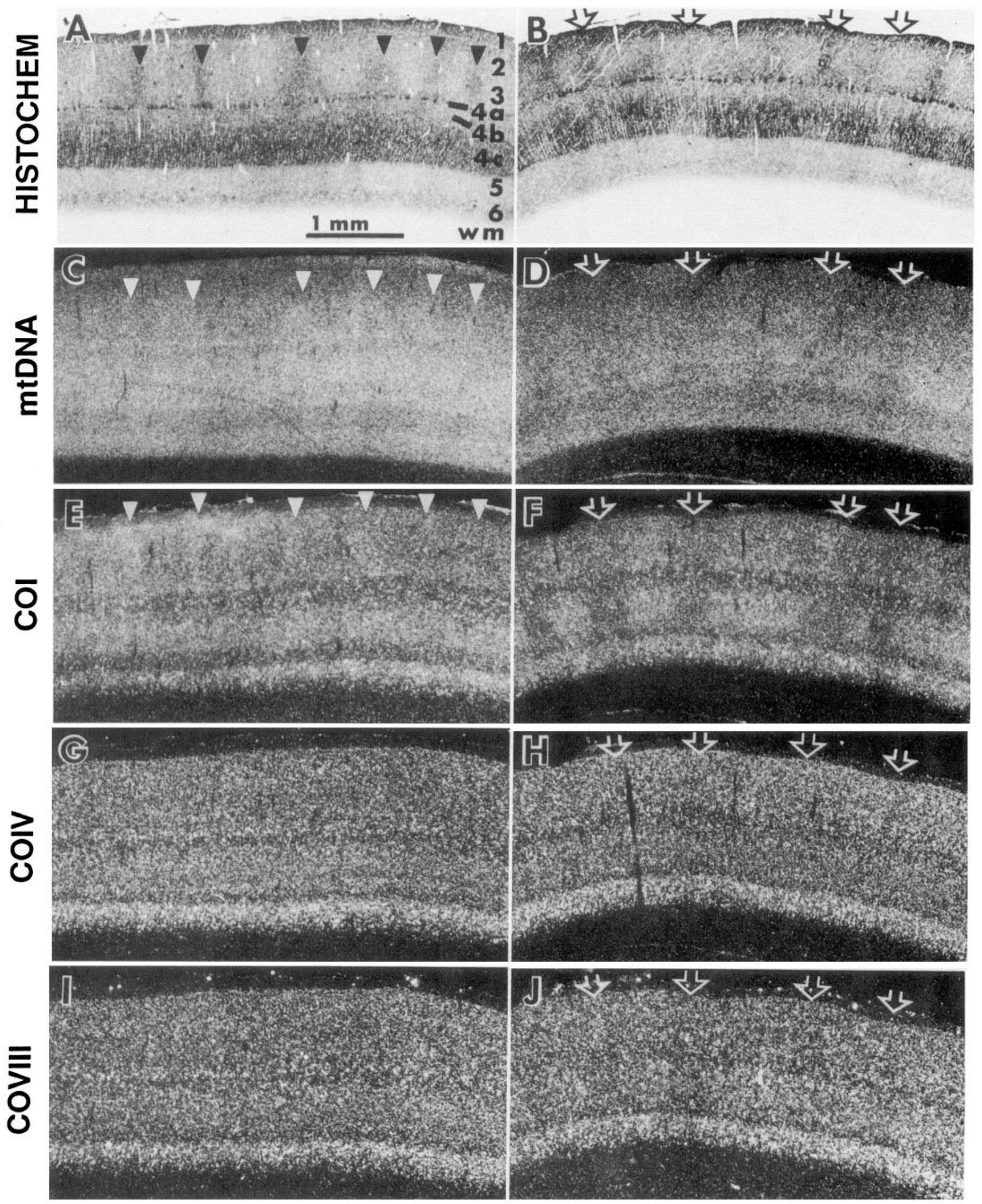
COIV mRNA, which decreased less than $\mathrm{CO}$ activity. There was no strict proportionality in the percentage change (ipsilateral vs. contralateral) between mitochondrial- and nuclear-encoded mRNAs, or between mtDNA and COI mRNA.

In situ hybridization: striate cortex

Figure 7 shows the distributions of CO activity, mtDNA, and CO subunit mRNAs in cortex from normal and $7 \mathrm{~d}$ TTX-treated animals. In normal cortex, the closest similarity to the $\mathrm{CO}$ activity pattern demonstrated histochemically (Fig. $7 A$ ) was seen for mtDNA (Fig. $7 C$ ). The relative levels of these two markers were similar in different cortical layers; layer $4 \mathrm{c}$ had the highest levels, and the puffs of high $\mathrm{CO}$ activity in layers 2-3 were enriched in both markers. Layer 4 a was labeled discontinuously for mtDNA, as for CO histochemistry. COI mRNA was more concentrated in cell bodies than were mtDNA and CO activity, but had an overall laminar distribution parallel to those markers (Fig. $7 E$ ). The puffs in layers $2-3$ were also prominently labeled for COI mRNA. COIV (Fig. $7 G$ ) and COVIII (Fig. $7 I$ ) mRNAs were highly concentrated in cell bodies, and were present at highest levels in cortical layer 6 (and to some extent in the lower hall of layer 5). Neither of these nuclear-encoded mRNAs was enriched in the layer $2-3$ puffs.

To examine more thoroughly the relation between puffs, mtDNA, and CO subunit mRNAs, we processed tangential sections of normal cortex by in situ hybridization (Fig. 8). The puffs are usually seen more clearly in tangential than in perpendicular sections stained for $\mathrm{CO}$ histochemistry, and this proved to be true for in situ hybridization material as well. Puffs were seen in neighboring tangential sections processed for $\mathrm{CO}$ histochemistry (Fig. 8A), mtDNA (Fig. 8B), and COI mRNA (Fig. 8C), but not in sections processed for COIV or COVIII mRNA (not shown). Thus, the results from tangential (Fig. 8) and perpendicular sections (Fig. 7) were in full agreement regarding puffs and each marker.

The effects of TTX treatment were analyzed using perpendicular (Fig. 7) and tangential (Fig. 9) sections of cortex. After $7 \mathrm{~d}$ of TTX, decreased levels of all five markers were seen in the same ocular dominance columns, corresponding to the treated eye. Cortical changes were also seen after $3 \mathrm{~d}$ of TTX, but were not as prominent (not shown). All five markers decreased most in layer $4 \mathrm{c}$, where ocular dominance segregation is most complete, and where the heaviest input from LGN is received (reviewed by Hubel and Wiesel, 1977). The greatest magnitude of change was seen for COI mRNA, while the least change was seen for COIV mRNA. The TTX-induced changes in COIV mRNA were difficult to see in perpendicular sections of cortex (Fig. $7 H$ ), but were clearly visible in tangential sections (Fig. 9D).

Notably, the columns of decreased COIV and COVIII mRNAs were narrower than the columns of decreased $\mathrm{CO}$ activity, mtDNA, and COI mRNA in the TTX-treated animals (Figs. 7, 9). The zones of decreased mtDNA and COI mRNA usually appeared to be about the same width as the columns of decreased CO activity; the zones of decreased COIV and COVIII mRNA, however, were always much narrower than the columns of decreased $\mathrm{CO}$ activity. This was most evident in tangential sections (Fig. 9). The tangential sections also showed more clearly that COI mRNA expression declined in columns in the supragranular cortical layers, as well as in layer $4 \mathrm{c}$ (Fig. 9C). $\mathrm{CO}$ activity also declined in supragranular columns (Fig. 9A).

We did not quantify the mtDNA and mRNA changes in striate cortex by grain counting. Qualitatively, however, the pattern of changes was the same in both cortex and LGN: COI changed the most, COIV changed the least, and the other markcrs showed intermediate changes. These alterations of gene expression were seen through several synapses, from retina, to LGN, to cortical layer 4 , to the supragranular cortical layers.

\section{Discussion}

The present study demonstrates that $\mathrm{CO}$ activity in neurons is regulated through complex changes in both mitochondrial and nuclear gene expression. These data provide a basis for comparison of $\mathrm{CO}$ regulation in neurons with that in other cell types, such as muscle, and indicate that mitochondrial energy metabolism in neurons is actively regulated at the genetic level. The in situ hybridization method was furthermore found to be a useful complement to $\mathrm{CO}$ histochemistry and immunohistochemistry for studying energy metabolism and its relation to neuronal functional activity in brain tissue. Indeed, our results suggest that $\mathrm{CO}$ subunit mRNAs may be regarded as molecular markers for ncuronal metabolic and functional activity.

\section{Disproportionate regulation of mitochondrial and nuclear MRNA expression}

Our major finding was that mitochondrial and nuclear gene expression were disproportionately regulated subsequent to alterations of functional activity in neurons. Depending on the

$\leftarrow$

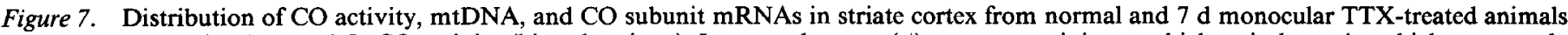

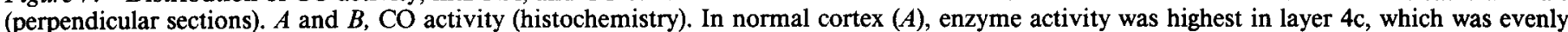

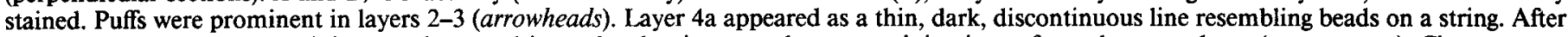

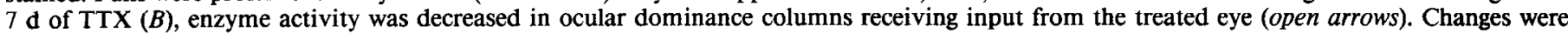

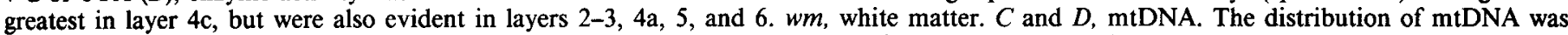

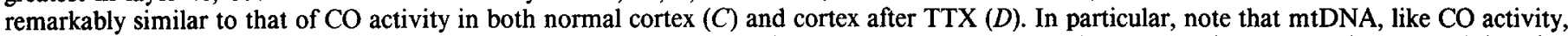

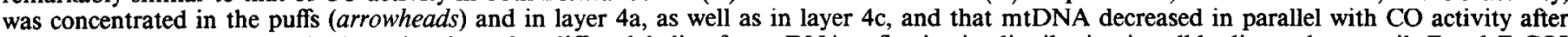

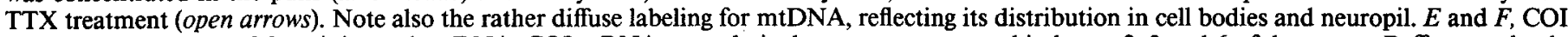

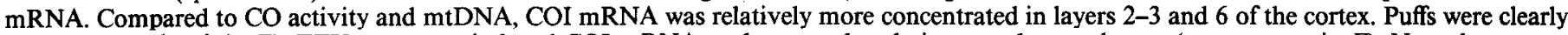

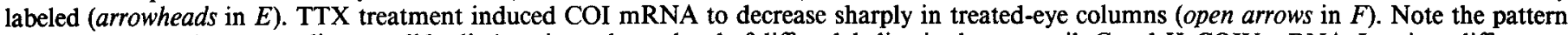

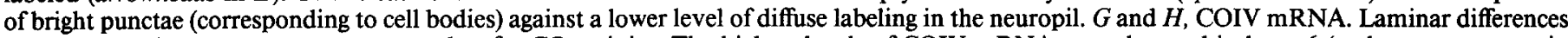

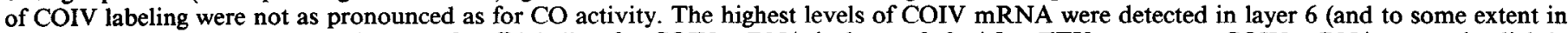

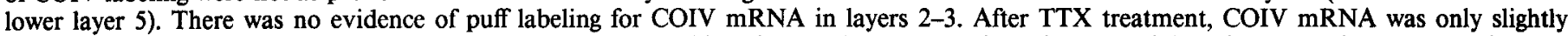

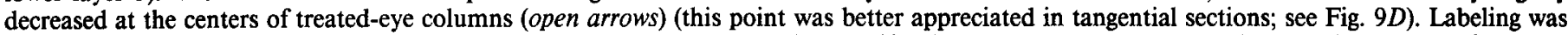

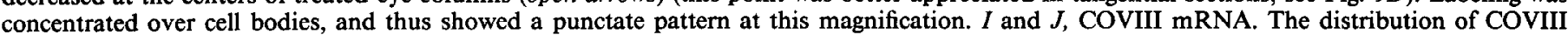

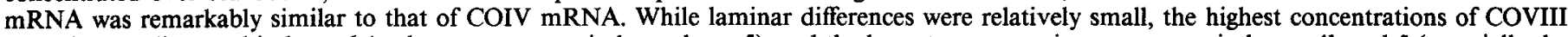

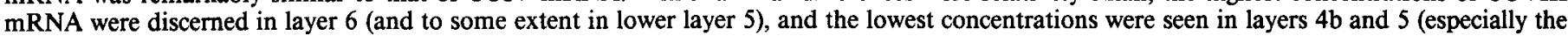

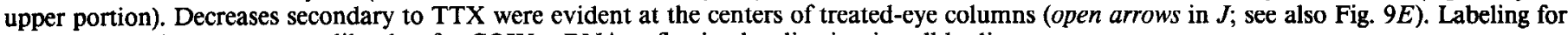
COVIII mRNA was punctate, like that for COIV mRNA, reflecting localization in cell bodies. 


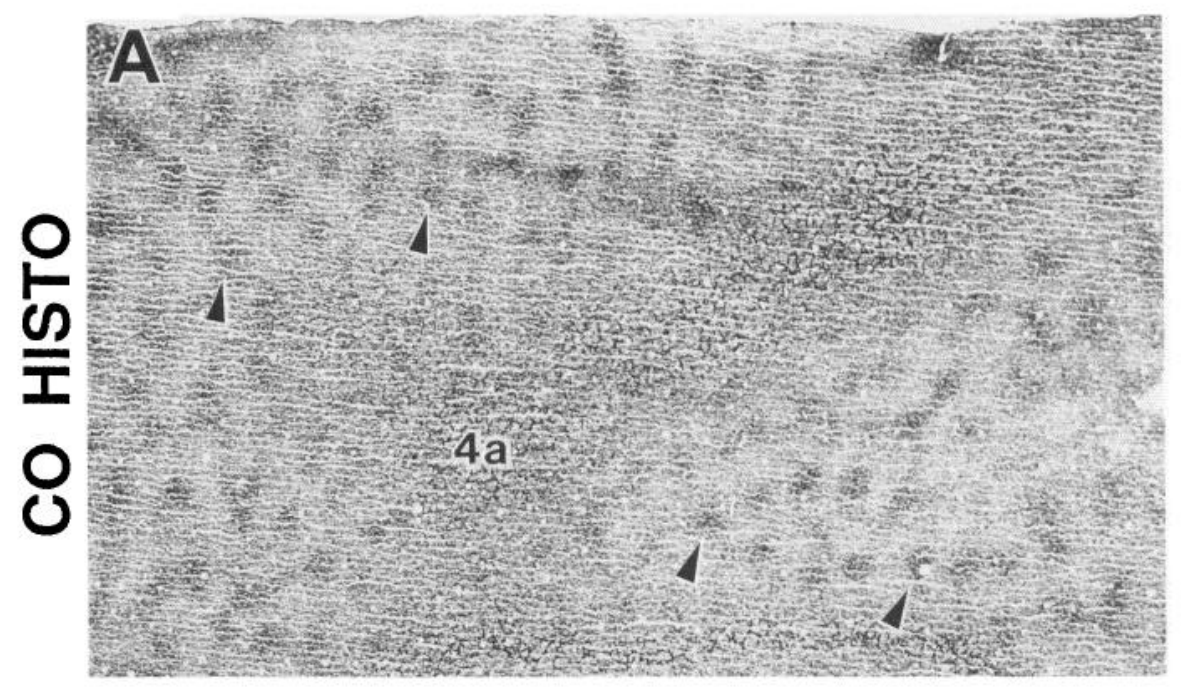

Figure 8. Puffs in layers 2-3 of striate cortex labeled in tangential sections reacted for $\mathrm{CO}$ activity, mtDNA, and $\mathrm{COI}$ mRNA. Neighboring sections from the same series are shown. No evidence of puff labeling was seen for COIV or COVIII mRNA (not shown). $A, \mathrm{CO}$ activity (histochemistry). The puffs were seen as spots of dark $\mathrm{CO}$ staining in layers 2-3. This section also passes through a portion of layer $4 a$, which had a honeycomb appearance in tangential sections. The arrowheads indicate some individual puffs that were also recognized in the sections reacted for mtDNA and COI mRNA. $B$, mtDNA. The puffs had moderately increased labeling for mtDNA. Arrowheads indicate puffs corresponding to those labeled in $A$ and $C$. The holes in this section were artifacts of tissue processing. $C$, COI mRNA. The puffs contained relatively high levels of COI mRNA. Arrowheads indicate puffs corresponding to those labeled in $A$ and $B$.
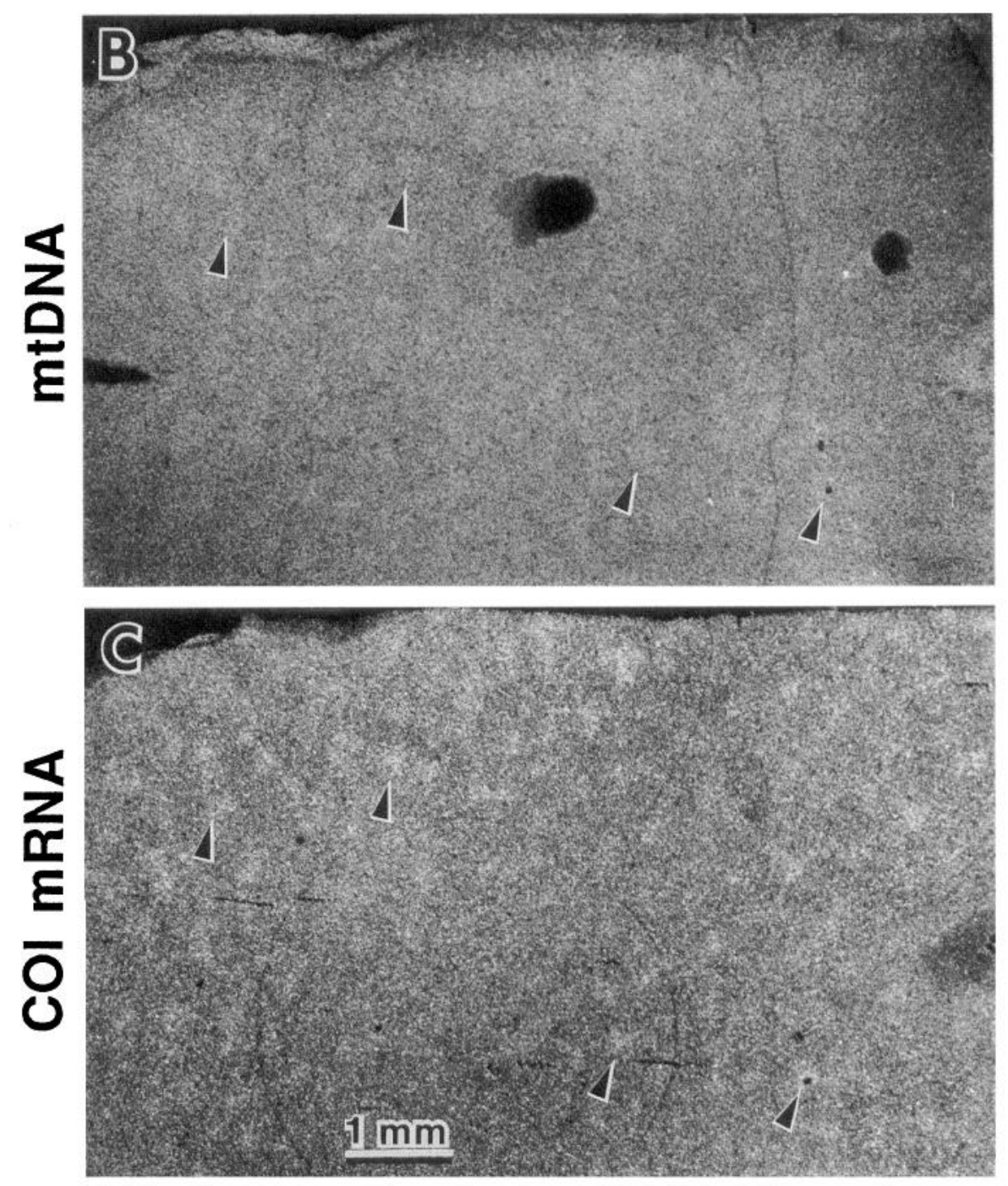

duration of TTX treatment, COI mRNA (mitochondrial) decreased between 2- and 3-fold more than COIV mRNA (nuclear), and 1.5- and 4-fold more than COVIII mRNA (also nuclear). This demonstrates that COI mRNA is regulated more tightly than nuclear-encoded CO subunit mRNAs in neurons.
It is not yet clear whether the same is true in other cell types; studies of muscle have yielded inconsistent results concerning this question. The ratio of mitochondrial- to nuclear-encoded CO subunit mRNAs appears to be constant among normal rat tissues (Hood, 1990; Gagnon et al., 1991). Alterations of func- 
CO HISTO

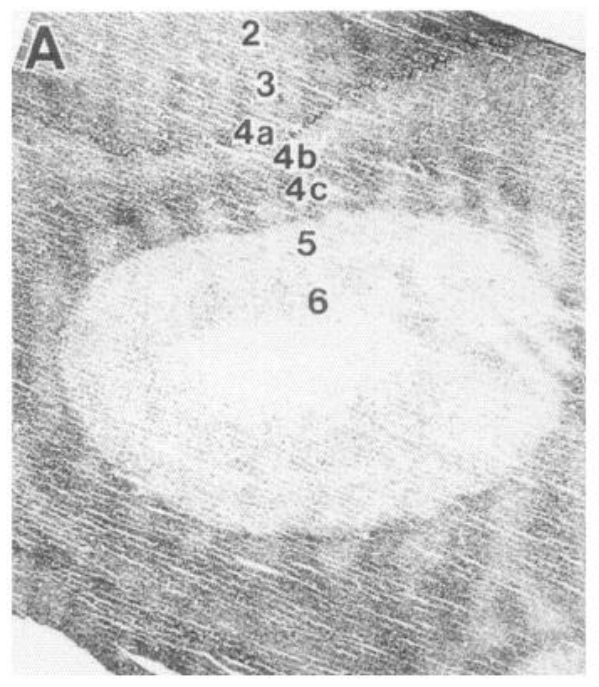

mtDNA
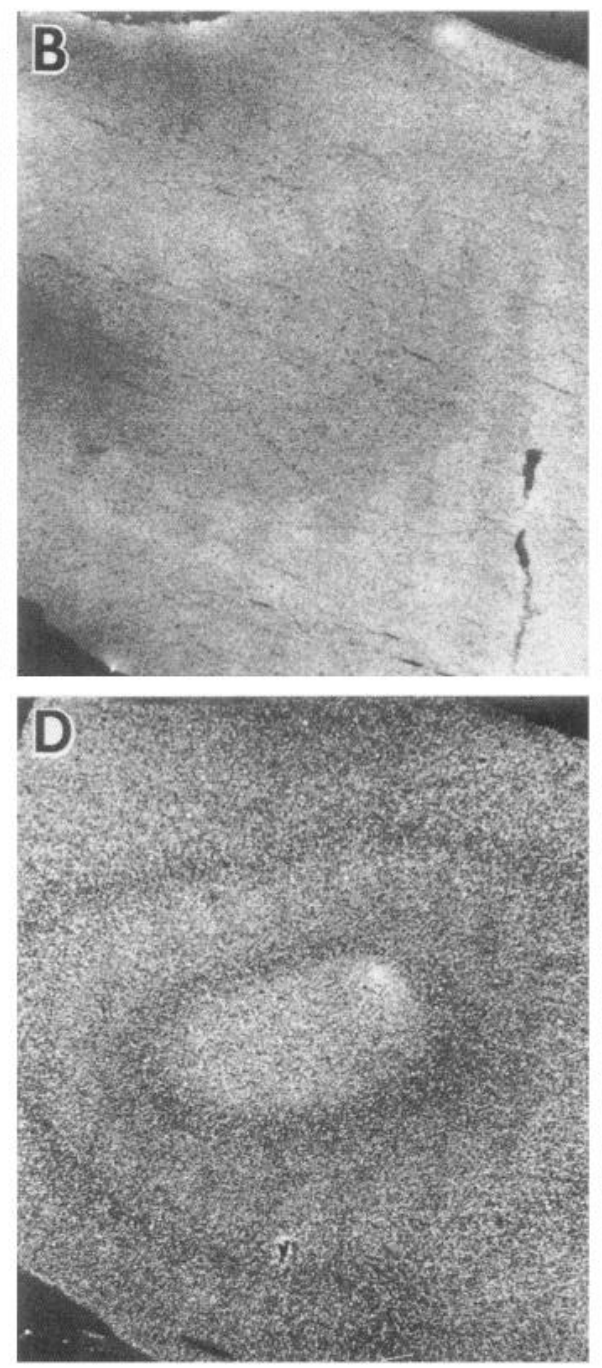

COIV mRNA

\section{COI mRNA}
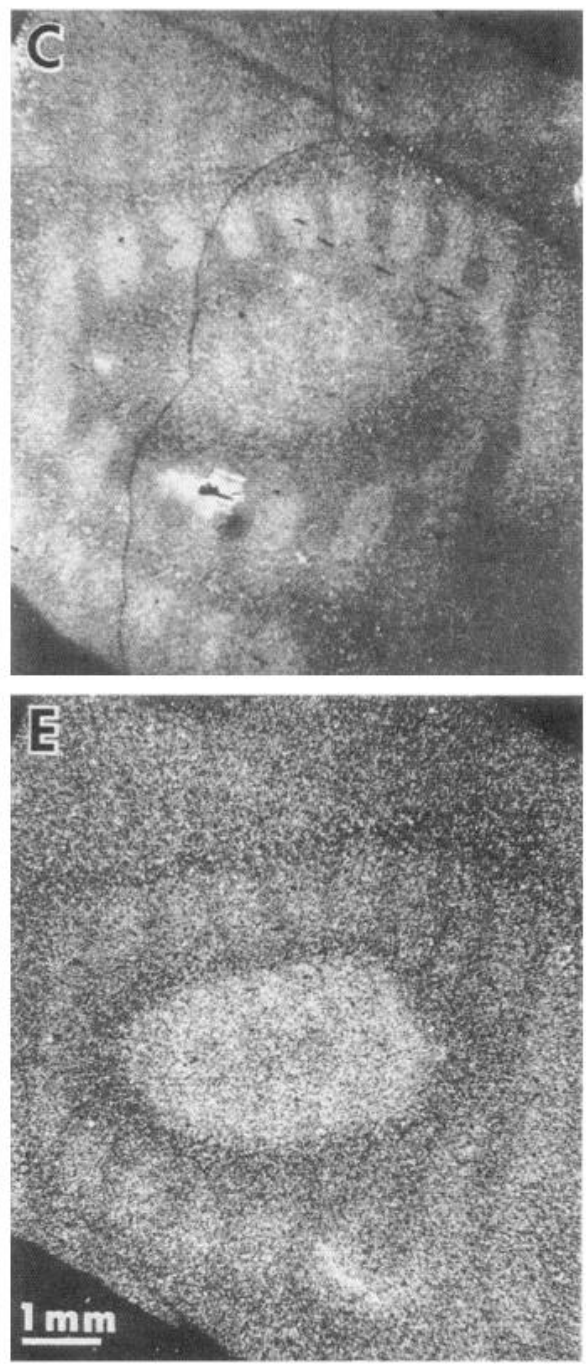

COVIII mRNA

Figure 9. Effects of monocular TTX (7 d) on CO activity, mtDNA, and CO subunit mRNAs in striate cortex (tangential sections). A, CO activity (histochemistry). Ocular dominance banding was evident in layers 2-3, 4a, 4c, 5, and 6. The greatest decreases were seen in treated-eye columns in the lower half of layer $4 \mathrm{c}(4 \mathrm{c} \beta)$. Note that the columns of dark $\mathrm{CO}$ staining (photographed with bright field) correspond to the columns of bright in situ hybridization signal (photographed with dark field) in $B-E . B, \mathrm{mtDNA}$. Changes were clearly evident in layer 4c, and appeared faintly in layers $2-3$. The width of decreased mtDNA columns appeared about the same as for $C O$ activity. $C$, COI mRNA. Decreases were seen in the same layers as for $\mathrm{CO}$ activity, and likewise were greatest in layer $4 \mathrm{c}$. The width of columnar decreases also appeared about same as for CO activity. $D$, COIV mRNA. Ocular dominance banding was clear in layer 4c. However, the width of columns affected was narrower for COIV mRNA than for CO activity. E, COVIII mRNA. Decreases were essentially identical as for COIV mRNA, except that there was some suggestion of ocular dominance banding extending into layers 2-3 and 6. Columns with decreased COVIII mRNA in layer 4c were narrower than columns with decreased CO activity.

tional activity, however, may disrupt the normal ratios: Williams et al. (1987) found that cytochrome $b$ mRNA (mitochondrial) increased threefold more than COVIc mRNA (nuclear) after $21 \mathrm{~d}$ of muscle stimulation. Contrary to those findings, Hood et al. (1989) reported that COIII mRNA (mitochondrial) increased only slightly more than COVIc mRNA (nuclear) after a $22 \mathrm{~d}$ stimulation period.

It is possible that differential regulation of mitochondrial mRNAs could account for the conflicting results regarding nuclear-mitochondrial coordination in neurons and muscle cells. Since the mitochondrial $\mathrm{H}$-strand is transcribed as a single polycistronic unit (Attardi and Schatz, 1988), transcriptional changes would be unlikely to account for differential regulation of $\mathrm{mi}$ - tochondrial mRNAs. However, these mRNAs have relatively short half-lives, on the order of $60 \mathrm{~min}$ in HeLa cells (Gelfand and Attardi, 1981), and selective mRNA stabilization could be a mechanism for differentially regulating mitochondrial mRNA levels.

\section{Mitochondrial $m R N A$ and $m$ tDNA copy number}

In animal cells, mitochondria are the only organelles that contain genes outside the nucleus. Each mitochondrion contains at least one copy of the circular mtDNA molecule, and on average several copies of the mitochondrial genome are present per mitochondrion (Bogenhagen and Clayton, 1974). Thus, a single neuron may contain dozens to thousands of copies of mtDNA. 
Since changes in the copy number of mtDNA would affect the rate of mitochondrial mRNA transcription, mRNA expression could be controlled by regulation of the mtDNA copy number.

We found that mtDNA levels were regulated, and decreased remarkably by $\sim 25 \%$ in LGN neurons after $7 \mathrm{~d}$ of TTX treatment. This indicates that mtDNA is not a static repository of genetic information, but instead is an active molecule susceptible to rapid and potent regulation. The mechanisms controlling mtDNA replication and turnover are not well understood at present, but they clearly must be responsive to signals concerning cellular metabolic demand. The finding that mtDNA copy number is a control point for respiratory metabolism in neurons is consistent with reports that mtDNA undergoes robust synthesis and turnover (half-life, $\sim 30 \mathrm{~d}$ ) in rat brain (Gross et al., 1969; Wondford and Blanks, 1989). The mtDNA copy number is also regulated in muscle by contractile activity (Williams, 1986; Williams et al., 1986).

Our data give no indication of whether the number of mitochondria changes or remains constant under conditions inducing regulation of mtDNA levels. Electron microscopic analysis has shown that the fraction of tissue volume occupied by mitochondria decreases in specific cortical puffs after monocular TTX treatment (Wong-Riley et al., 1989a,b). Schwerzmann et al. (1989) likewise showed that contractile stimulation induced the fractional volume of mitochondria to increase in muscle, but possible changes in the number of mitochondria were not assessed.

TTX-induced changes in the mtDNA copy number did not account for the full magnitude of changes in COI (mitochondrial) mRNA expression. COI mRNA declined by almost $50 \%$ after $7 \mathrm{~d}$ of TTX, while mtDNA declined by only $\sim 25 \%$. This twofold difference implies that not only the gene copy number, but also the rates of COI mRNA transcription and/or turnover were regulated. In muscle, however, levels of mtDNA and cytochrome $b$ mRNA (mitochondrial) increased proportionately after contractile stimulation, implying that increases in mitochondrial mRNA were secondary to elevated mtDNA levels (Williams, 1986; Williams et al., 1986). This inconsistency between our results and those from muscle suggests that there may be tissue-specific differences in mitochondrial regulatory mechanisms.

The molecular mechanisms controlling mitochondrial mRNA transcription and turnover are generally not well understood at present. Since the D-loop region of mtDNA contains the origins for both replication and transcription of the $\mathrm{H}$-strand, it is possible that transcription and replication might be regulated jointly (Attardi and Schatz, 1988; Clayton, 1991). This would be consistent with our results regarding the disproportionate changes in COI mRNA and mtDNA levels induced by TTX. The role of mitochondrial DNA polymerase, and mRNA transcription factors (Kelly et al., 1986; Masters et al., 1987; Fisher et al., 1989) in regulation of mitochondrial gene expression could be investigated in the visual system using the TTX paradigm, and immunohistochemistry and in situ hybridization to detect the mitochondrial regulatory molecules.

\section{Regulation of nuclear mRNAs}

The great majority of mitochondrial polypeptides are nuclear encoded (Attardi and Schatz, 1988), and many polypeptides are stoichiometric subunits of the same enzymes. Are the nuclearencoded mRNAs for mitochondrial polypeptides regulated proportionately? Our present results show some disproportion be- tween COIV and COVIII mRNA regulation in LGN neurons. In liver, different nuclear-encoded mRNAs are regulated disproportionately in response to thyroid hormone treatment (Virbasius and Scarpulla, 1990). The ratio of cytochrome $c$ mRNA to COIV mRNA (both nuclear encoded) also differs among rat tissues (Virbasius and Scarpulla, 1990). The promoter regions of nuclear respiratory genes, including $\mathrm{CO}$ subunit genes, contain different regulatory elements (Suske et al., 1988; Virbasius and Scarpulla, 1990; Yamada et al., 1990; Basu and Avadhani, 1991). In agreement with these other data, our results suggest that levels of the nuclear-encoded mRNAs for mitochondrial polypeptides are regulated independently.

\section{CO protein regulation}

A corollary of the proposition that $\mathrm{CO}$ activity is controlled by regulation of $\mathrm{mRNA}$ and $\mathrm{mtDNA}$ levels is that CO protein levels should change in direct proportion with $\mathrm{CO}$ activity. In the present study, we obtained densitometric evidence that $\mathrm{CO}$ activity and protein decreased proportionately in cortex after 3$7 \mathrm{~d}$ of TTX treatment. This extends our previous work showing that changes were proportionate after $28 \mathrm{~d}$ of TTX (Hevner and Wong-Riley, 1990). Likewise, in muscle, stimulation-induced increases of $\mathrm{CO}$ activity were blocked by chloramphenicol inhibition of mitochondrial protein synthesis (Williams and Harlan, 1987). These data suggest that $\mathrm{CO}$ activity is regulated entirely by control of $\mathrm{CO}$ protein levels. Other studies, however, have found evidence that the molecular activity of $\mathrm{CO}$ may be regulated by isozyme switching or by conformational effects of ATP binding (Huther and Kadenbach, 1986; Bisson et al., 1987; Gai et al., 1988; Ewart et al., 1991).

\section{Distribution of CO mRNAs and mtDNA in LGN and cortex}

In both LGN and cortex, major differences were observed in the distributions of mtDNA, COI mRNA (mitochondrial), and COIV and COVIII mRNAs (nuclear). To understand these regional differences, it is important to consider the subcellular distribution of each molecule. As shown in our previous report (Hevner and Wong-Riley, 1991), mtDNA is located throughout neurons, COI mRNA is present in cell bodies and dendrites, and COIV and COVIII mRNAs are restricted mainly or exclusively to cell bodies and proximal dendrites.

In LGN, the intralaminar distribution of each molecular species was a direct reflection of its subcellular localization. Thus, mtDNA was distributed diffusely within each layer, and was only modcratcly concentrated in cell bodies; COI mRNA was highly concentrated in cell bodies, but was also seen in neuropil; and COIV and COVIII mRNAs were found only in cell bodies and proximal dendrites. Interlaminar differences were observed only for COI mRNA (mitochondrial), which was highest in layer 1 of the normal LGN. CO activity was also highest in layer 1 neurons, confirming previous densitometric results (Liu and Wong-Riley, 1990).

In striate cortex, more complicated patterns of mtDNA and mRNA expression were seen. While mtDNA and COI mRNA levels were relatively parallel to $\mathrm{CO}$ activity in each layer, COIV and COVIII mRNAs were highly concentrated in layer 6 (and to some extent lower layer 5) neurons. This may indicate that layer VI neurons have exceptionally high requirements for $\mathrm{CO}$ synthesis. In this regard, it is useful to remember that all of the COIV and COVIII mRNA molecules in neurons are located in the cell body and proximal dendrites; thus, COIV and COVIII mRNA levels in the cell body are probably determined by the 
overall $\mathrm{CO}$ needs of the whole neuron, including dendrites and axon. In contrast, mtDNA and COI mRNA are distributed intraneuronally to sites of high local oxidative metabolism, so levels of these markers in the cell body more likely reflect local, rather than overall, neuronal demands.

This same principle is useful for analyzing the relation between $\mathrm{CO}$ gene expression and puffs in layers 2-3. The puffs were cnriched in mtDNA and COI mRNA, but not COIV or COVIII mRNA. Since CO activity in puffs is concentrated in dendrites (Carroll and Wong-Riley, 1984; Wong-Riley et al., 1989a,b), only mtDNA and COI mRNA, but not COIV or COVIII mRNAs, would follow a parallel distribution. Also, most puff neurons extend dendrites into both puff and interpuff territories (Malach, 1992), so cell bodies in puffs would be unlikely to have significantly elevated COIV or COVIII mRNA levels.

Similar arguments explain the narrow width of columnar changes in COIV and COVIII mRNAs in striate cortex from TTX-treated animals. The zones of decreased COIV and COVIII mRNAs corresponded only to the centers of histochemically defined columns; this indicates that the regulation of nuclearencoded mRNAs was blunted near column borders. Since cell bodies near ocular dominance column borders extend dendrites into adjacent columns (Katz et al., 1989), it is possible that border-zone neurons continued to receive significant functional and metabolic activation via the adjacent-column dendrites even during TTX treatment, and that the effects of TTX on COIV and COVIII mRNA levels were thus attenuated. We think that only neurons in column centers, whose dendrites were confined to the home column, received no adjacent-column input during treatment, and that TTX effects on COIV and COVIII mRNA levels were thus seen only in ocular dominance column centers.

In contrast, the zones of decreased mtDNA and COI mRNA were about the same width as histochemically defined columns. These data, and the observations regarding layer 2-3 puffs, suggest that mtDNA and COI mRNA are regulated locally with high spatial resolution in subcellular compartments, while COIV and COVIII mRNAs are regulated globally in accordance with the integrated metabolic activity of the whole neuron. This raises an important question for future studies: if the nucleus controls mtDNA replication and transcription (Attardi and Schatz, 1988), then how are mtDNA and COI mRNA levels regulated differentially among separate processes belonging to the same neuron?

\section{Importance of mitochondrial $m R N A$ in $C O$ regulation}

Our results point to COI mRNA (mitochondrial), and thus possibly all of the cotranscribed H-strand mRNAs (Attardi and Schatz, 1988), as key molecules in the regulation of respiratory capacity. First, COI was the only mRNA that was, like CO activity (Liu and Wong-Riley, 1990), higher in layer 1 than in other LGN layers. Second, our qualitative and quantitative results indicated that COI mRNA was more tightly regulated than were the nuclear-encoded mRNAs. Third, COI mRNA (but not COIV or COVIII mRNA) was elevated in cortical puffs, and followed ocular dominance column boundaries faithfully after TTX treatment. In each example, $\mathrm{CO}$ activity was linked more closely to COI mRNA (mitochondrial) than to COIV or COVIII mRNA (both nuclear). The fact that the mitochondrial $\mathrm{H}$-strand is transcribed as a unit (Attardi and Schatz, 1988) implies that the other mitochondrial-encoded $\mathrm{CO}$ subunit mRNAs (COII and COIII) are probably also linked closely to $\mathrm{CO}$ activity. The close relation between $\mathrm{CO}$ activity and mitochondrial mRNA levels suggests that mitochondrial mRNA regulation plays the major role in controlling local $\mathrm{CO}$ activity in neurons. This would not be surprising, given that the catalytic centers of the enzyme reside in the mitochondrial-encoded subunits (Azzi and Müller, 1990; Capaldi, 1990).

\section{Mitochondrial genes and neurologic disease}

In the last decade, specific mutations of milochondrial DNA have been identified as the causes of distinct neuromuscular and neuro-ophthalmologic diseases (reviewed by Harding, 1991). A perplexing aspect of these diseases is that the clinical features differ markedly among the various mitochondrial mutations; for example, visual loss is the main feature of Leber's hereditary optic neuropathy, while stroke-like episodes predominate in the MELAS syndrome. Now that the mutations underlying these and several other mitochondrial diseases have been characterized, the question remains as to how each mutation gives rise to particular clinical manifestations. In this regard, in situ hybridization could be a valuable tool for localizing mitochondrial mRNA and mtDNA molecules in brain tissue from afflicted human patients and animal models. Our present results, showing that mitochondrial genes are tightly regulated, suggest that aberrant regulation and/or localization of mitochondrial gene expression might play a role in these diseases; this hypothesis could be tested directly using in situ hybridization methods.

\section{Does mitochondrial gene expression sometimes limit neuronal functional capabilities?}

Neurons derive their metabolic energy utilizing the aerobic pathway almost exclusively (Erecinska and Silver, 1989). Thus, regulation of mitochondrial gene expression probably exerts a major influence on the capacity of neurons for energy production and consumption. Energy consumption, in turn, is tightly coupled to neuronal functional activity (Kennedy et al., 1975, 1976), mainly becausc of the high metabolic cost of ion pumping in active neurons (Mata et al., 1980; Erecinska and Silver, 1989; Hevner et al., 1992). On the basis of these considerations, we hypothesize that regulation of mitochondrial genes may, through metabolic effects, have a significant effect on neuronal functional capabilities. We have previously emphasized that neuronal activity regulates energy metabolism (Wong-Riley, 1989), but in some cases (such as the mitochondrial genetic diseases), energy metabolism may limit neuronal activity. For example, neurons with relatively low mitochondrial reserve might fail to maintain ionic concentration gradients within normal physiological limits during periods of intense activity; the abnormal ion gradients would alter membrane potential, and could conceivably cause sustained depolarization or hyperpolarization, perhaps resulting in excitotoxicity, seizures, or dysregulation of neurotransmitter metabolism. This hypothesis could be tested using physiological methods to study cultured neurons treated with mitochondrial inhibitors, or animal models of mitochondrial diseases. Just as enhanced energy metabolism is needed for improving strength in muscles, optimal function may depend on a robust metabolic capacity in neurons.

\section{References}

Attardi G, Schatz G (1988) Biogenesis of mitochondria. Annu Rev Cell Biol 4:289-333.

Azzi A, Müller M (1990) Cytochrome $c$ oxidases: polypeptide composition, role of subunits, and location of active metal centers. Arch Biochem Biophys 280:242-251. 
Basu A Avadhani NG (1991) Structural organization of nuclear gene for subunit $\mathrm{Vb}$ of mouse mitochondrial cytochrome $c$ oxidase. J Biol Chem 266:15450-15456.

Bisson R, Schiavo G, Montecucco C (1987) ATP induces conformational changes in mitochondrial cytochrome $c$ oxidase. Effect on the cytochrome $c$ binding site. J Biol Chem 262:5992-5998.

Bogenhagen D, Clayton DA (1974) The number of mitochondrial deoxyribonucleic acid genomes in mouse $\mathrm{L}$ and human $\mathrm{HeLa}$ cells. J Biol Chem 249:7991-7995.

Capaldi RA (1990) Structure and assembly of cytochrome c oxidase. Arch Biochem Biophys 280:252-262.

Carroll EW, Wong-Riley MTT (1984) Quantitative light and electron microscopic analysis of cytochrome oxidase-rich zones in the striate cortex of the squirrel monkey. J Comp Neurol 222:1-17.

Clayton DA (1991) Nuclear gadgets in mitochondrial DNA replication and transcription. Trends Biochem Sci 16:107-111.

DiFiglia M, Graveland GA, Schiff L (1987) Cytochrome oxidase activity in the rat caudate nucleus: light and electron microscopic observations. J Comp Neurol 255:137-145.

Erecinska M, Silver IA (1989) ATP and brain function. J Cereb Blood Flow Metab 9:2-19.

Ewart GD, Zhang Y-Z, Capaldi RA (1991) Switching of bovine cytochrome oxidase subuniti VIa isoforms in skeletal muscle during development. FEBS Lett 292:79-84.

Fisher RP, Parisi MA, Clayton DA (1989) Flexible recognition of rapidly evolving promoter sequences by mitochondrial transcription factor 1. Genes Dev 3:2202-2217.

Gagnon J, Kurowski TT, Wiesner RJ, Zak R (1991) Correlations between a nuclear and a mitochondrial mRNA of cytochrome $c$ oxidase subunits, enzymatic activity and total mRNA content, in rat tissues. Mol Cell Biochem 107:21-29.

Gai W-Z, Sun S-M, Ding Y-Z, Freedman JS, Chan SHP (1988) Two monoclonal antibody lines directed against subunit IV of cytochrome oxidase: a study of opposite effects. Arch Biochem Biophys 266:628638.

Gelfand R, Attardi G (1981) Synthesis and turnover of mitochondrial ribonucleic acid in HeLa cells: the mature ribosomal and messenger ribonucleic acid species are metabolically unstable. Mol Cell Biol $1: 497-511$.

Gross NJ, Getz GS, Rabinowitz M (1969) Apparent turnover of mitochondrial deoxyribonucleic acid and mitochondrial phospholipids in the tissues of the rat. J Biol Chem 244:1552-1562.

Harding AE (1991) Neurological disease and mitochondrial genes. Trends Neurosci 14:132-138.

Hevner RF, Wong-Riley MTT (1989) Brain cytochrome oxidase: purification, antibody production, and immunohistochemical/histochemical correlations in the CNS. J Neurosci 9:3884-3898.

Hevner RF, Wong-Riley MTT (1990) Regulation of cytochrome oxidase protein levels by functional activity in the macaque monkey visual system. J Neurosci 10:1331-1340.

Hevner RF, Wong-Riley MTT (1991) Neuronal expression of nuclear and mitochondrial genes for cytochromc oxidase $(\mathrm{CO})$ subunits analyzed by in situ hybridization: comparison with $\mathrm{CO}$ activity and protein. J Neurosci 11:1942-1958.

Hevner RF, Duff RS, Wong-Riley MTT (1992) Coordination of ATP production and consumption in brain: parallel regulation of cytochrome oxidase and $\mathrm{Na}^{+}, \mathrm{K}^{+}$-ATPase. Neurosci Lett 138:188-192.

Hood DA (1990) Co-ordinate expression of cytochrome $c$ oxidase subunit III and VIc mRNAs in rat tissues. Biochem J 269:503-506.

Hood DA, Zak R, Pette D (1989) Chronic stimulation of rat skeletal muscle induces coordinate increases in mitochondrial and nuclear mRNAs of cytochrome- $c$ - oxidase subunits. Eur J Biochem 179:275280.

Horton JC, Hubel DH (1981) Regular patchy distribution of cytochrome oxidase staining in primary visual cortex of macaque monkey. Nature 292:762-764.

Hubel DH, Wiesel TN (1977) Functional architecture of macaque monkey visual cortex. Proc R Soc Lond [Biol] 198:1-59.

Huther F-J, Kadenbach B (1986) Specific effects of ATP on the kinetics of reconstituted bovine heart cytochrome-c oxidase. FEBS Lett 207: 89-94.

Kadenbach B, Jarausch J, Hartmann R, Merle P (1983) Separation of mammalian cytochrome $c$ oxidase into 13 polypeptides by a sodium dodecyl sulfate-gel electrophoretic procedure. Anal Biochem 129:517-521.

Kageyama GH, Wong-Riley MTT (1982) Histochemical localization of cytochrome oxidase in the hippocampus: correlation with specific neuronal types and afferent pathways. Neuroscience 7:2337-2361.

Katz LC, Gilbert CD, Wiesel TN (1989) Local circuits and ocular dominance columns in monkey striate cortex. J Neurosci 9:13891399.

Kelly JL, Greenleaf AL, Lehman IR (1986) Isolation of the nuclear gene encoding a subunit of the yeast mitochondrial RNA polymerase. J Biol Chem 261:10348-13051.

Kennedy C, Des Rosiers MH, Jehle JW, Reivich M, Sharpe F, Sokoloff L (1975) Mapping of functional ncural pathways by autoradiographic survey of local metabolic rate with $\left[{ }^{14} \mathrm{C}\right]$ deoxyglucose. Science 187 : $850-853$.

Kennedy C, Des Rosiers MH, Sakurada O, Shinohara M, Reivich M, Jehl JW, Sokoloff L (1976) Metabolic mapping of the primary visual system of the monkey by means of the autoradiographic $\left[{ }^{14} \mathrm{C}\right]$ deoxyglucose technique. Proc Natl Acad Sci USA 73:4230-4234.

Liu S, Wong-Riley M (1990) Quantitative light- and electron-microscopic analysis of cytochrome-oxidase distribution in neurons of the lateral geniculate nucleus of the adult monkey. Vis Neurosci 4:269287.

Malach R (1992) Dendritic sampling across processing streams in monkey striate cortex. J Comp Neurol 31 5:303-312.

Masters BS, Stohl LL, Clayton DA (1987) Yeast mitochondrial RNA polymerase is homologous to those cncoded by bacteriophages T3 and T7. Cell 51:89-99.

Mata M, Fink DJ, Gainer H, Smith CB, Davidsen L, Savaki H, Schwartz WJ, Sokoloff L (1980) Activity-dependent energy metabolism in rat posterior pituitary primarily reflects sodium pump activity. J Neurochem 34:213-215.

Mjaatvedt AE, Wong-Riley MTT (1988) Relationship between synaptogenesis and cytochrome oxidase activity in Purkinje cells of the developing rat cerebellum. J Comp Neurol 277:155-182.

Schwerzmann K, Hoppeler H, Kayar SR, Weibel ER (1989) Oxidative capacity of muscle and mitochondria: correlation of physiological, biochemical, and morphometric characteristics. Proc Natl Acad Sci USA 86:1583-1587.

Suske G, Enders C, Schlerf A, Kadenbach B (1988) Organization and nucleotide sequence of two chromosomal gencs for rat cytochrome $c$ oxidase subunit VIc: a structural and a processed gene. DNA 7:163171.

Virbasius JV, Scarpulla RC (1990) The rat cytochrome $c$ oxidase subunit IV gene family: tissue-specific and hormonal differences in subunit IV and cytochrome $c$ mRNA expression. Nucleic Acids Res 18: 6581-6586.

Weiss LT, Chesselet M-F (1989) Regional distribution and regulation of preprosomatostatin messenger RNA in the striatum, as revealed by in situ hybridization histochemistry. Mol Brain Res 5:121-130.

Williams RS (1986) Mitochondrial gene expression in mammalian striated muscle: evidence that variation in gene dosage is the major regulatory event. J Biol Chem 261:12390-12394.

Williams RS, Harlan W (1987) Effects of inhibition of mitochondrial protein synthesis in skelctal musclc. Am J Physiol 253:C866-C871.

Williams RS, Salmons S, Newsholme EA, Kaufman RE, Mellor J (1986) Regulation of nuclear and mitochondrial gene expression by contractile activity in skeletal muscle. J Biol Chem 261:376-380.

Williams RS, Garcia-Moll M, Mellor J, Salmons S, Harlan W (1987) Adaptation of skeletal muscle to increased contractile activity: expression of nuclear genes encoding mitochondrial proteins. J Biol Chem 262:2764-2767.

Wong-Riley M (1979) Changes in the visual sysstem of monocularly sutured or enucleated cats demonstrable with cytochrome oxidase histochemistry. Brain Res 171:11-28.

Wong-Riley MTT (1989) Cytochrome oxidase: an endogenous metabolic marker for neuronal activity. Trends Neurosci 12:94-101.

Wong-Riley M, Carroll EW (1984) Effect of impulse blockage on cytochrome oxidase activity in monkcy visual system. Nature 307:262264.

Wong-Riley MTT, Welt C (1980) Histochemical changes in cytochrome oxidase of cortical barrels after vibrissal removal in neonatal and adult mice. Proc Natl Acad Sci USA 77:2333-2337.

Wong-Riley MTT, Tripathi SC, Trusk TC, Hoppe DA (1989a) Effect of retinal impulse blockage on cytochrome oxidase-rich zones in the macaque striate cortex: I. Quantitative electron-microscopic (EM) analysis of neurons. Vis Neurosci 2:483-497.

Wong-Riley MTT, Trusk TC, Tripathi SC, Hoppe DA (1989b) Effect of retinal impulse blockage on cytochrome oxidase-rich zones in the 
macaque striate cortex: II. Quantitative electron-microscopic (EM) analysis of neuropil. Vis Neurosci 2:499-514.

Woodford BJ, Blanks JC (1989) Uptake of tritiated thymidine in mitochondria of the retina. Invest Ophthalmol Vis Sci 30:2528-2532.
Yamada M, Amuro N, Goto Y, Okazaki T (1990) Structural organization of the rat cytochrome $c$ oxidase subunit IV gene. J Biol Chem 265:7687-7692. 